Article Type: Original Article

\title{
NDP-MSH reduces oxidative damage induced by palmitic acid in primary astrocytes
}

Delia Ramírez ${ }^{1}$, Julieta Saba ${ }^{1}$, Juan Turati ${ }^{1}$, Lila Carniglia ${ }^{1}$, Mercedes Imsen $^{1}$, Claudia Mohn $^{2}$, Teresa Scimonelli ${ }^{3}$, Daniela Durand ${ }^{1}$, Carla Caruso ${ }^{1}$, Mercedes Lasaga ${ }^{1 *}$

${ }^{1}$ INBIOMED - Instituto de Investigaciones Biomédicas, UBA-CONICET, School of Medicine, University of Buenos Aires, Argentina.

${ }^{2}$ Department of Physiology, School of Dentistry, University of Buenos Aires, Argentina. ${ }^{3}$ IFEC-CONICET, Pharmacology Department, School of Chemistry, National University of Cordoba, Argentina.

\section{${ }^{\star}$ Corresponding author:}

Mercedes Lasaga, PhD

Instituto de Investigaciones Biomédicas, UBA-CONICET

Paraguay 2155, piso 10, Buenos Aires 1121, Argentina

E-mail: mlasaga@fmed.uba.ar

Abbreviated title: NDP-MSH reduces PA-induced oxidative damage

Key words: MC4R, astrocytes, oxidative stress, palmitic acid, high fat diet

This article has been accepted for publication and undergone full peer review but has not been through the copyediting, typesetting, pagination and proofreading process, which may lead to differences between this version and the Version of Record. Please cite this article as doi: $10.1111 /$ jne. 12673

This article is protected by copyright. All rights reserved. 


\section{ABSTRACT}

Recent findings relate obesity to inflammation in key hypothalamic areas for body weight control. Hypothalamic inflammation has also been related to oxidative stress. Palmitic acid (PA) is the most abundant free fatty acid found in food, and in vitro studies indicate that it triggers a pro-inflammatory response in the brain. Melanocortins are neuropeptides with proven anti-inflammatory and neuroprotective action mediated by melanocortin receptor 4 (MC4R), but little is known about the effect of melanocortins on oxidative stress. The aim of this study was to investigate whether melanocortins could alleviate oxidative stress induced by a high fat diet (HFD) model. We found that NDP-MSH treatment decreased PA-induced reactive oxygen species (ROS) production in astrocytes, an effect blocked by the MC4R inhibitor JKC363. NDP-MSH abolished nuclear translocation of Nrf2 induced by PA and blocked the inhibitory effect of PA on superoxide dismutase (SOD) activity and glutathione (GSH) levels while it also per se increased activity of SOD and $\gamma$-glutamate cysteine ligase $(\gamma-G C L)$ antioxidant enzymes. However, HFD reduced hypothalamic MC4R and BDNF mRNA levels, thereby preventing the neuroprotective mechanism induced by melanocortins.

\section{INTRODUCTION}

Obesity has developed as a major health concern, its rate of incidence tripling since 1975. According to the World Health Organization, in 2016 more than 1.9 billion adults 18 years and older were overweight and over 650 million were obese. If this trend continues, it is estimated that $51 \%$ of the world's adult population will be obese by $2030^{1}$.

Consumption of high fat diets (HFD) is crucial for the development of obesity. Excessive intake of fatty acids induces a chronic low-grade inflammatory response that affects both peripheral tissues and central nervous system $(\mathrm{CNS})^{2}$.In vivo studies have shown that highfat feeding increases cytokine levels and pro-inflammatory signaling in the hypothalamus through TLR4 activation ${ }^{3}$, leading to neuronal death ${ }^{4}$ and leptin and insulin signaling impairment $^{2,5}$. Interestingly, hypothalamic inflammation appears long before the onset of peripheral inflammation, metabolic disturbances, and weight gain 6 .

This article is protected by copyright. All rights reserved. 
Inflammation and oxidative stress are linked in obesity. Pro-inflammatory signaling pathways activated in obesity increase production of reactive oxygen species (ROS) ${ }^{7}$ which, in turn, exacerbate the inflammatory response ${ }^{8}$. Moreover, disturbances in antioxidant enzyme activity and increase in oxidative stress markers have been found in plasma of obese animals ${ }^{9}$. Saturated fatty acids are known to induce neurotoxicity and oxidative stress in the CNS. Palmitic acid (PA) is the most abundant free fatty acid found in food, and in vitro studies indicate that PA induces TNF- $\alpha, \mathrm{IL}-1 \beta$ and IL-6 release in astrocytes and microglia $^{10,11}$. In addition, PA increases ROS production in astrocytes ${ }^{12}$. In the hypothalamus, astroglial cells are involved in detection and transport of nutrients ${ }^{13}$ and also express receptors for hormones and neuropeptides whose activation directly affects neurons that control metabolic homeostasis ${ }^{14}$. HFD also induces reactive gliosis, a phenomenon that persists after the onset of obesity ${ }^{2}$. Activated astrocytes promote blood brain barrier disruption $^{15}$, enhancement of diet reward properties in the mesolimbic system ${ }^{16}$, and synaptic changes in the melanocortin system ${ }^{17}$, thereby perpetuating diet-induced obesity.

Melanocortins are a group of neuropeptides that includes adrenocorticotropic hormone and $\alpha, \beta$ and $\gamma$-melanocyte-stimulating hormones (MSH) which have protective actions in the brain $^{18,19}$. Melanocortin actions are mediated by their five receptor subtypes (MC1R to MC5R). In the CNS, MC4R is the most widely distributed subtype. $\alpha-M S H$, the endogenous MC4R agonist, has a physiological effect on feeding and energy homeostasis. $\alpha-M S H$ also exerts neuroprotective effects in different in vivo models of ischemia and inflammation by decreasing the expression of pro-inflammatory cytokines ${ }^{20}$ and inducing neurogenesis with functional recovery ${ }^{21}$. Our group determined that both astrocytes and microglia express MC4R ${ }^{22,23}$ and we also demonstrated that MC4R mediates the anti-inflammatory effect of melanocortins in astrocytes ${ }^{22}$, microglia ${ }^{23}$, and hypothalamus ${ }^{19}$. While anti-inflammatory actions of melanocortins in the CNS have been studied, the melanocortin effect on antioxidant response was explored only in skin cells where $\alpha-\mathrm{MSH}$ reduces ROS production and stimulates antioxidant defenses ${ }^{24}$. Considering that melanocortins have proven antiinflammatory and neuroprotective actions, we tested the effect of $\left[\mathrm{Nle}^{4}, \mathrm{D}-\mathrm{Phe}^{7}\right]-\alpha-$ 
melanocyte-stimulating hormone (NDP-MSH), an $\alpha-\mathrm{MSH}$ analogue, on oxidative damage induced by saturated fatty acids in vitro and in vivo, in order to evaluate its potential as a modulator of metabolic disorders.

\section{MATERIALS AND METHODS}

\subsection{Reagents}

$\left[\mathrm{Nle}^{4}, \mathrm{D}-\mathrm{Phe} \mathrm{7}^{7}\right]-\alpha-\mathrm{melanocyte}-\mathrm{stimulating}$ hormone (NDP-MSH) was purchased from Bachem (CA, USA). Sodium palmitate was purchased from Santa Cruz Biotechnology (TX, USA). Bovine serum albumin, Fraction V, fatty acid free was obtained from Roche (Grenzach, Germany). JKC363 was purchased from Tocris Bioscience (MO, United States). Fetal bovine serum (FBS) was obtained from Natocor (Cordoba, Argentina). Nrf2 antibody (Novus) was kindly provided by Dr. Cymeryng (CEFYBO, UBA-CONICET). DMEM/F-12, DMEM, LGlutamine and antibiotics were purchased from Invitrogen Life Technologies (CA, USA). All other media and supplements were obtained from Sigma-Aldrich Corporation unless specified otherwise.

\subsection{Cell cultures}

Primary astrocyte culture: Astrocytes were prepared from rat cerebral cortex tissue of 1- to 2-day old postnatal Wistar rat pups as described previously ${ }^{22}$. Cells were maintained in DMEM/F-12 medium containing10\% FBS, $50 \mu \mathrm{g} / \mathrm{ml}$ streptomycin, $50 \mathrm{U}$ penicillin in $75 \mathrm{~cm}^{2}$ poly-L-lysine coated culture flasks at $37^{\circ} \mathrm{C}$ in $5 \% \mathrm{CO}_{2}$. Cell culture medium was changed twice a week. Cells were trypsinized and subcultured and, after 2-3days of stabilization, incubated with the drugs in MEM containing $6 \mathrm{mM} \mathrm{L-glutamine,} 50 \mu \mathrm{g} / \mathrm{ml}$ streptomycin, and $50 \mathrm{U} / \mathrm{ml}$ penicillin. Cultures were routinely more than $95 \%$ pure astrocytes as assessed by glial fibrillary acidic protein (GFAP) immunostaining.

Cell treatments: Sodium palmitate was conjugated to bovine serum albumin (BSA) after both components were first solubilized separately as described by Pike Winer ${ }^{25}$. Briefly, sodium palmitate was solubilized in $150 \mathrm{mM} \mathrm{NaCl}$ by heating it to $70^{\circ} \mathrm{C}$ in a water bath. Fatty 
acid-free BSA was dissolved in $150 \mathrm{mM} \mathrm{NaCl}$ and warmed up to $37^{\circ} \mathrm{C}$ with continuous stirring. Solubilized PA was combined with BSA at a molar ratio of 6:1 (PA/BSA), stirring at $37^{\circ} \mathrm{C}$ for $1 \mathrm{~h}$, and the final concentration was set at $1 \mathrm{mM}$. The conjugated PA-BSA was aliquoted and stored at $-20^{\circ} \mathrm{C}$. Vehicle stock solution was prepared using the same protocol without PA. Astrocytes were incubated with PA and NDP-MSH alone or in combination for 2 $\mathrm{h}$ to determine ROS generation, for $6 \mathrm{~h}$ to evaluate Nrf2 nuclear translocation and gene expression and for $24 \mathrm{~h}$ to determine enzymatic activity. Control astrocytes were incubated with vehicle solution.

\subsection{In vivo experiments}

Animals: Two month old male Wistar Kyoto rats were obtained from the School of Veterinary Science, National University of La Plata. At the start of the experiment the animals were weighted (mean body weight: $286.22 \pm 4.64 \mathrm{~g}$ ) and were randomly assigned to either a standard diet (SD, Asociación Cooperativas Argentinas, having the following composition, w/w: $23 \%$ proteins, $5 \%$ fat, $6 \%$ fibre, $10 \%$ minerals and $56 \%$ starch and vitamin supplements) or a high-fat diet (HFD; $50 \%$ w/w bovine fat added to SD), as described by Lee et $\mathrm{al}^{26}$. There were no significant differences in body weight between groups before the experimental diets were administered, as all rats had been kept on a regular chow diet. Rats were housed in standard caging with a 12/12 h light/dark cycle and ad libitum access to water and their respective diet unless otherwise noted. HFD was replaced daily to avoid rancidity. Rats were administered the HFD or SD for 8 weeks. Energy concentrations were $2900 \mathrm{kcal} / \mathrm{kg}$ for SD and $5950 \mathrm{kcal} / \mathrm{kg}$ for HFD.

Cannulations: After 7 weeks on the HFD or SD diet, cannulas were placed under stereotaxic guidance into either the right or left lateral cerebral ventricle of the rats as described by Caruso ${ }^{19}$. Briefly, rats were anesthetized with Xylazine $(10 \mathrm{mg} / \mathrm{kg}$ ) and Ketamine $(50 \mathrm{mg} / \mathrm{kg})$ and placed into a stereotaxic frame. A 22-gauge guide sleeve was lowered into either the right or the left lateral cerebral ventricle according to the coordinates of Paxinos and Watson ${ }^{27}$ (coordinates: A-P $-0.6 \mathrm{~mm}, \mathrm{~L}-/+2 \mathrm{~mm}, \mathrm{D}-\mathrm{V}-3.2 \mathrm{~mm}$ )and then 
secured to the skull with screws and dental acrylic. Animals were placed in individual cages and allowed to recover for 7 days.

Procedure: Animals were fasted overnight and on the day of euthanasia rats received an intracerebroventricular (ICV) injection of either saline $(5 \mu \mathrm{l} / \mathrm{rat})$ or NDP-MSH $(1 \mu \mathrm{g} / 5 \mu \mathrm{l} / \mathrm{rat})$. During the next $4 \mathrm{~h}$, animals were fed and then euthanized by decapitation. Trunk blood was collected, allowed to clot at RT and spun at $3000 \mathrm{rpm}$ for $10 \mathrm{~min}$; plasma was separated and stored at $-20^{\circ} \mathrm{C}$ for further biochemical assay. After euthanasia, a hypothalamic fragment $(\mathrm{MBH})$ that included the arcuate and periventricular nuclei and the median eminence was dissected and immediately processed for either RT-qPCR or enzymatic activity assay.

Caloric intake: Caloric intake was calculated by multiplying the amount $(\mathrm{g})$ of food consumed per day by the caloric concentration $(\mathrm{kcal} / \mathrm{g})$ of each diet.

Serum biochemical determinations: Serum glucose, triglycerides, cholesterol, and insulin were measured in a biochemical analysis lab (Buenos Aires, Argentina) that processes animal samples. Measurements were performed using enzymatic assays: glucose oxidase assay for glucose (sensitivity: $0.54 \mathrm{mg} / \mathrm{dl}$ ), glycerol-3-phosphate oxidase/peroxidase assay for triglycerides (sensitivity: $0.8 \mathrm{mg} / \mathrm{dl}$ ), cholesterol esterase/oxidase/peroxidase assay for cholesterol (sensitivity: $0.63 \mathrm{mg} / \mathrm{dl}$ ) and chemiluminescence assay for insulin (sensitivity: $0.03 \mu \mathrm{Ul} / \mathrm{ml})$.

TNF- $\alpha$ level: TNF- $\alpha$ concentration was measured using a commercial kit (Invitrogen) following the manufacturer's instructions. Assay sensitivity was $4 \mathrm{pg} / \mathrm{ml}$. All samples were run in duplicate in the same assay for all analyses.

\subsection{Superoxide dismutase (SOD) activity}

Total SOD activity was measured by the method described by Misra and Fridovich ${ }^{28}$. This method is based on the inhibition of superoxide-dependent epinephrine auto-oxidation in a spectrophotometer adjusted at $480 \mathrm{~nm}$. A $50 \%$ inhibition of epinephrine auto-oxidation is defined as one unit of SOD, and the specific activity (U SOD/mg protein) was expressed as a percentage of the control group.

This article is protected by copyright. All rights reserved. 


\section{5. $\gamma$-Glutamate cysteine ligase $(\gamma-G C L)$ activity}

The activity of $\gamma$-GCL was measured by a fluorescence-based microtiter plate assay as described by Correa et al. $^{29}$ with minor modifications. Briefly, after cell lysis and centrifugation, an aliquot was reserved for protein content analysis. Another aliquot was mixed with the reaction cocktail (400 mM Tris buffer, $20 \mathrm{mM} \mathrm{L-glutamic} \mathrm{acid,} 2$ mM EDTA, 20 $\mathrm{mM}$ sodium borate, and $40 \mathrm{mM}$ ATP freshly added). The reaction was initiated by adding 2 mM cysteine. After incubation, reaction was stopped with $200 \mathrm{mM} \mathrm{5-sulfosalicylic} \mathrm{acid.} \mathrm{The}$ amount of $\gamma$-glutamylcysteine $(\gamma$-GC) formed was measured by 2,3naphthalenedicarboxaldehyde (NDA, Invitrogen) fluorescence. Fluorescence was read in a Synergy HT microplate reader (Biotek, USA) at $485 \mathrm{~nm} / 528 \mathrm{~nm}$. $\gamma$-GCL activity was calculated in moles $\gamma-\mathrm{GC} / \mathrm{min} / \mathrm{mg}$ protein and presented as a percentage of control conditions.

\subsection{Glutathione (GSH) measurement}

GSH levels were determined by a fluorescence based assay ${ }^{30}$ with modifications. Astrocytes were treated for 2 or $24 \mathrm{~h}$, then conditioned medium was saved and cells were collected in Locke Buffer (10 mM HEPES, $5.5 \mathrm{mM} \mathrm{KCl,} 10 \mathrm{mM}$ glucose, $5 \mathrm{mM} \mathrm{NaHCO}_{3}$, and $130 \mathrm{mM}$ $\mathrm{NaCl}$ ). After sonication, cells were centrifuged at $12,000 \mathrm{rpm}$ for $30 \mathrm{~min}$. Supernatant aliquots were saved for protein determination by the Bradford assay. Conditioned medium and supernatant samples were diluted with an equal volume of 200 mM5-sulfosalicylic acid and kept on ice for $15 \mathrm{~min}$. After vigorously vortexing, samples were centrifuged at $12,000 \mathrm{rpm}$ for 3 min. $20 \mu \mathrm{l}$ standard curve of $\mathrm{GSH}$, supernatants and conditioned medium samples were loaded in a 96-well plate in duplicate. $180 \mu \mathrm{l} /$ well of NDA solution (50 mM Tris pH 10, $0.5 \mathrm{~N}$ $\mathrm{NaOH}, 10 \mathrm{mM}$ NDA) were added to every well and the plate was incubated for $30 \mathrm{~min}$ in the dark at RT. Fluorescence was read in a Synergy HT microplate reader (Biotek, USA) at 485 $\mathrm{nm} / 528 \mathrm{~nm}$.

This article is protected by copyright. All rights reserved. 


\subsection{Reactive oxygen species (ROS) determination}

Intracellular ROS levels were detected using 2'-7'-dichlorofluorescein diacetate (DCFH-DA) which when hydrolyzed within the cell is oxidized to fluorescent dichlorofluorescein (DCF) as described by Saba et al. ${ }^{31}$. Cells were seeded onto 96 -well plates at a density of $3 \times 10^{4}$ cells per well. They were pre-incubated with $10 \mu \mathrm{M}$ DCFH-DA for 30 minutes at $37^{\circ} \mathrm{C}$. Then, the cells were exposed to PA with or without $0.1 \mu \mathrm{M}$ NDP-MSH for $2 \mathrm{~h}$. Fluorescence intensity was measured using a Synergy HT microplate reader with filters at $485 \mathrm{~nm}$ excitation and $520 \mathrm{~nm}$ emission.

\subsection{Cell viability assay}

Cell viability was assessed by the 3-[4, 5-dimethylthiazol-2-yl]-2, 5-diphenyltetrazolium bromide (MTT) reduction assay ${ }^{32}$. Briefly, cells were washed in Krebs buffer and incubated for $4 \mathrm{~h}$ with $110 \mu \mathrm{l}$ of a $0.5 \mu \mathrm{g} / \mathrm{ml}$ MTT-Krebs buffer solution. Formazan crystals obtained from MTT reduction were dissolved in $100 \mu \mathrm{l}$ of a $0.04 \mathrm{~N} \mathrm{HCl}$-isopropanol solution. OD was measured in a microplate spectrophotometer (Bio-Rad) at $595 \mathrm{~nm}$ and presented as a percentage of control conditions.

\subsection{Immunocytochemistry}

To examine the nuclear translocation of Nrf2, immunocytochemistry was performed following the Kundu et al. protocol ${ }^{33}$ with minor modifications. Cells were washed in PBS and fixed in 4\% paraformaldehyde (PFA) for 10 minutes at RT, permeabilized with PBS-triton $X 0.2 \%$, and blocked with PBS-Tween $0.1 \%+10 \%$ goat serum. Then, slides were incubated overnight at $4^{\circ} \mathrm{C}$ with anti-Nrf2 antibody (1:50, Novus). After washing in PBS, cells were further incubated with goat anti-rabbit IgG conjugated with fluorescein (1:200, Vector Laboratories)for 1 hour at RT. Slides were mounted in Vectashield mounting medium (Vector Laboratories). Negative control slides were incubated with blocking solution instead of the

This article is protected by copyright. All rights reserved. 
primary antibodies. Staining was visualized in a fluorescence microscope (Axiophot; Carl Zeiss, Jena, Germany). Quantification of fluorescence intensity was done with ImageJ Software (NIH, USA).

\subsection{Reverse transcriptase-real time polymerase chain reaction (RT-qPCR)}

Total RNA from cultured astrocytes $\left(1 \times 10^{6}\right.$ cells) and from hypothalamus was extracted using Trizol reagent (Invitrogen) following the manufacturer's protocol. Two micrograms of total RNA were treated with $1 \mathrm{U}$ RQ1 RNase free DNase (Promega Corporation, WI, USA) at $37^{\circ} \mathrm{C}$ for $10 \mathrm{~min}$, and reverse-transcribed as described before ${ }^{34}$. Products of the RT reaction were amplified using specific primers and SYBR Green Select Master Mix (Invitrogen Life Technologies) on a StepOne ${ }^{\mathrm{TM}}$ Real-Time PCR System (Applied Biosystems). Primer sequences are detailed in Table 1. PCR product specificity was verified by melting curve analysis. No-RT controls were performed by omitting the reverse transcriptase enzyme in the RT reaction, and no-template controls were performed by addition of nuclease-free water instead of cDNA. Gene expression was normalized to the endogenous reference gene HPRT by the $\Delta \Delta \mathrm{Ct}$ method ${ }^{35}$ using Step-One Software (Applied Biosystems), and expressed as fold-changes relative to the control group.

\subsection{Statistical analysis}

Data were analyzed by one sample t test, Student's t test, one-way analysis of variance (ANOVA) or two-way ANOVA followed by Bonferroni's multiple comparisons test, as required by the experimental design. GraphPad Prism 5 Software was used (GraphPad Software, CA, USA). Differences with a value of $p<0.05$ were considered statistically significant.

\subsection{Ethics Statement}

Experimental procedures were approved by the Institutional Committee for the Care and Use of Laboratory Animals (CICUAL) of the School of Medicine, University of Buenos Aires, 
Argentina (resolution $n^{\circ} 2746 / 2013$ ) and were carried out in compliance with the guidelines of the NIH Guide for the Care and Use of Laboratory Animals

\section{RESULTS}

\subsection{NDP-MSH prevented PA-induced ROS production in astrocytes}

In order to determine PA working concentration, we tested cell viability and ROS production in astrocytes exposed to different doses of PA. Astrocyte viability was not significantly different from control after treatment with PA at $50 \mu \mathrm{M}$ and $100 \mu \mathrm{M}$. However, concentrations of $200 \mu \mathrm{M}$ or higher induced cell death in a dose-dependent manner (Fig. 1a). PA also induced astrocyte ROS production in a concentration-dependent manner (Fig. 1b).

To test the effect of NDP-MSH on ROS production, cells were co-incubated for $2 \mathrm{~h}$ with PA $(100 \mu \mathrm{M})$ and NDP-MSH $(0.1 \mu \mathrm{M})$. We observed that ROS production was significantly decreased by NDP-MSH. To determine whether MC4R is involved in NDP-MSH effects on ROS production we treated cells with JKC363 (10 nM), a potent and selective MC4R antagonist. JKC363 completely blocked NDP-MSH effect on ROS levels induced by PA (Fig. 1c). Neither NDP-MSH nor JKC363 alone modified basal ROS levels (Fig. 1c).

\subsection{PA activated the Nrf2 pathway in astrocytes}

Nrf2 is the master transcription factor that regulates basal and inducible expression of antioxidant proteins, detoxifying enzymes and xenobiotic transporters ${ }^{36}$. In basal conditions, Nrf2 is located in the cytoplasm; when activated, it migrates to the nucleus ${ }^{36}$. Since PA exhibits pro-oxidant properties, we evaluated the effect of PA on Nrf2 activation by determining its intracellular localization by immunocytochemistry. Astrocytes were exposed to $100 \mu \mathrm{M}$ PA with or without $0.1 \mu \mathrm{M}$ NDP-MSH co-incubation for $6 \mathrm{~h}$. Treatment with PA strongly increased Nrf2 nuclear translocation and NDP-MSH co-treatment reduced nuclear fluorescence intensity compared to PA alone (Fig. 2a). Interestingly, NDP-MSH alone decreased Nrf2 nuclear translocation compared to control conditions (Fig. 2b).

This article is protected by copyright. All rights reserved. 
Next, we investigated whether these results correlated with mRNA levels of Nrf2-dependent genes. $\gamma$-GCL catalytic subunit (GCLc), $\gamma$-GCL modifier subunit (GCLm) and hemeoxygenase 1 (HO-1) gene expression were evaluated by RT-qPCR. PA increased mRNA levels of GCLc (Fig 2c), GCLm (Fig. 2d), and HO-1 (Fig. 2e), whereas PA+NDP-MSHtreatment decreased them. Surprisingly, NDP-MSH alone did not modify their expression.

Brain derived neurotrophic factor (BDNF) plays an important role in neuronal survival and it has been reported to prevent oxidative damage in primary neuronal cultures and neuronal cell lines by increasing GSH levels and activity of antioxidant enzymes ${ }^{37}$. Our group demonstrated that melanocortins stimulate BDNF expression in astrocytes ${ }^{34}$, and therefore we tested NDP-MSH effect on PA-challenged astroglial cells. PA reduced BDNF gene expression, an effect significantly prevented by NDP-MSH co-incubation. As we reported before, NDP-MSH alone increased BDNF mRNA levels (Fig. 2f)

\subsection{NDP-MSH enhanced SOD and $\gamma$-GCLactivity in astrocytes}

To determine the mechanism by which NDP-MSH reduced ROS levels we evaluated the activity of SOD and $\gamma$-GCL antioxidant enzymes. NDP-MSH increased SOD activity 2-fold compared to control conditions after $24 \mathrm{~h}$ of incubation (Fig. 3a). Under PA-oxidative insult, SOD activity was reduced by about $65 \%$ compared to basal value and this effect was completely prevented by NDP-MSH (Fig. 3a).NDP-MSH markedly increased the enzymatic activity of $\gamma$-GCL in a dose-dependent manner (Fig. 3b). Notably, a remarkable 5-fold increase was observed in the presence of PA+NDP-MSH (Fig. 3c), even though PA alone did not change $\gamma$-GCL activity.

\subsection{NDP-MSH increased GSH levels in astrocytes}

GSH is the main endogenous antioxidant compound, its rate of synthesis depending on $\gamma$ GCL activity. Considering that NDP-MSH reduced PA-induced ROS production while increasing $\gamma$-GCL activity, as a next step, we evaluated the effect of this melanocortin on intracellular and extracellular levels of GSH. 24 h-treatment with NDP-MSH did not modify 
GSH intracellular levels but stimulated GSH extracellularly (Fig. 4a). However, when NDP$\mathrm{MSH}$ was co-incubated with PA for $2 \mathrm{~h}$, it enhanced both intracellular and extracellular GSH concentrations (Fig. 4b and c). In both cases, PA itself did not modify GSH production (Fig. $4 b$ and $c)$.

\subsection{Effect of HFD and NDP-MSH on calorie intake and biochemical parameters}

$\alpha-\mathrm{MSH}$ plays a key role in energy homeostasis, inhibiting feeding behavior through MC4R activation. Our group has studied anti-inflammatory actions of melanocortins in the CNS, showing that MC4R is involved in this effect, but little is known about a possible effect of melanocortins on the oxidative component of inflammation. Therefore, we decided to investigate the effect of NDP-MSH treatment on the antioxidant response in animals fed a HFD. To do so, rats were exposed to either SD ( $5 \%$ fat) or HFD (50\% fat) for 8 weeks. Daily calorie intake and weight gain were registered during this period. As expected, HFD-fed rats consumed more calories than SD group (Fig. 5a). However, after the 8th week of exposure to each diet, there were no differences in weight gain (Fig. 5b). At the end of the experiment, animals were fasted overnight, and then injected ICV with saline or NDP-MSH, re-fed, and euthanized $4 \mathrm{~h}$ later.

Figure 6a depicts 4-h calorie intake in response to NDP-MSH in SD and HFD groups. Consistent with reported anorexigenic actions of melanocortins, NDP-MSH treatment reduced calorie intake in SD-fed rats. However, this effect was not observed in animals exposed to HFD. Biochemical determinations showed that HFD per se did not modify any parameter. NDP-MSH reduced serum glucose levels in SD and HFD groups (Fig. 6b). Triglyceride levels markedly decreased upon NDP-MSH stimulation in SD-fed rats. In contrast, this effect was not observed in animals fed a HFD (Fig. 6c). NDP-MSH impact on serum insulin levels differed in function of the diet administered, inducing an increase in SD group (Fig. 6d) and a decrease in HFD group ( $p=0.0603$ ). Treatment did not modify serum cholesterol levels (Fig. 6e) in either SD or HFD-fed animals. As we mentioned before, high fat-feeding triggers inflammation impacting on key hypothalamic areas involved in body

This article is protected by copyright. All rights reserved. 
weight regulation ${ }^{2}$. Considering the anti-inflammatory actions of melanocortins, we measured TNF- $\alpha$ production in our model. Surprisingly, neither diet nor NDP-MSH altered serum levels of this cytokine.

\subsection{Effect of HFD and NDP-MSH on the antioxidant response}

We investigated the effect of NDP-MSH treatment on antioxidant response in the hypothalamus. We observed that after $4 \mathrm{~h}$ of treatment NDP-MSH increased SOD activity in SD-fed rats (Fig. 7a), but had no effect on animals exposed to HFD. Moreover, HFD by itself did not modify SOD activity (Fig. 7a). Next, we studied Nrf2 pathway byRT-PCR, determining Nrf2, GCLm, and GCLC mRNA levels. Neither NDP-MSH nor HFD significantly modified expression of the aforementioned genes (Fig. 7b, c and d).

\subsection{Effect of HFD and NDP-MSH on BDNF and MC4R expression}

BDNF has been reported to exert antioxidant action, and its hypothalamic expression augments in response to melanocortins ${ }^{38}$. For this reason, we evaluated BDNF and MC4R expression in our model. HFD reduced mRNA levels of BDNF (Fig. 8a) and MC4R (Fig. 8b) and, consistent with the lack of effect of NDP-MSH on biochemical and antioxidant parameters upon HFD exposure, NDP-MSH did not revert the decrease in MC4R and BDNF expression induced by the diet. Surprisingly, NDP-MSH did not increase expression of these genes in the SD group, an effect we previously detected when a-MSH was administered by intraperitoneal injection ${ }^{39}$. On the contrary, we found that in cultured astrocytes PA (100 $\left.\mu \mathrm{M}\right)$ induced a 34\% reduction in MC4R mRNA levels compared to control group, while coincubation with NDP-MSH $(0.1 \mu \mathrm{M})$ induced a significant $46.6 \%$ increase in MC4R expression compared to control group, indicating that NDP-MSH might act differentially in whole hypothalamic tissue than in astrocytes.

This article is protected by copyright. All rights reserved. 


\section{DISCUSSION}

Obesity has been associated with chronic low-grade inflammation that affects peripheral tissues and the CNS. Saturated fatty acids are elevated in plasma of obese patients ${ }^{40}$. Since they can cross the blood brain barrier they contribute to activation of glial cells by triggering neuroinflammation ${ }^{41}$ which may lead to neurodegeneration. Oxidative damage is involved in the pathogenesis of metabolic diseases and HFD has been reported to trigger oxidative stress $^{42}$. Moreover, PA induces expression of pro-inflammatory cytokines in astrocytes ${ }^{10}$ and apoptosis of neurons and astrocytes by increasing oxidative stress ${ }^{43}$. Astrocytes perform several physiological functions to maintain brain homeostasis, and their involvement in obesity-related processes is beginning to be understood. Melanocortins exert antiinflammatory and neuroprotective effects on the $\mathrm{CNS}^{18,22}$. However, antioxidant effects of melanocortins in the brain are unknown. Therefore, we investigated the effect of NDP-MSH, an $\alpha-\mathrm{MSH}$ analogue, on oxidative stress in PA-treated astrocytes and in a model of HFD. In the present work we demonstrated that melanocortins exerted antioxidant actions in astrocyte and in the hypothalamus of male rats.

PA-stimulated ROS production has been studied in different cells including astrocytes ${ }^{12}$. In this study, we report for the first time that NDP-MSH, through MC4R, reduces ROS levels in astrocytes challenged with PA. Astrocytes are key players in defense against oxidative insults $^{37}$. In an oxidative context, astroglial cells respond by changing the expression of several genes regulated by Nrf2, the master redox transcription factor. Previous studies have shown that PA induces Nrf2 expression in hepatocyte primary cultures ${ }^{44}$ and in the normal liver cell line $\mathrm{QZG}^{45}$. Furthermore, PA activates Nrf2 pathway in mouse hepatoma and in mouse embryonic fibroblast cell lines ${ }^{46} . \alpha-\mathrm{MSH}$ also reverses oxidative stress induced by UV radiation through Nrf2 activation in human skin cells ${ }^{24}$. Our experiments showed that Nrf2 and its target genes GCLc, GCLm and HO-1 were positively regulated by PA and that NDP-MSH reversed this effect. Considering that both pro-oxidant compounds and ROS stimulate Nrf2 nuclear translocation, PA-induced Nrf2 activation may be mediated by

This article is protected by copyright. All rights reserved. 
increased ROS levels. Given that NDP-MSH reduces ROS production, we suggest that ROS reduction could be responsible for NDP-MSH inhibitory action on Nrf2 nuclear translocation. Interestingly, NDP-MSH alone reduced Nrf2 translocation without modifying ROS levels. JNK and p38 MAPK have been reported to induce Nrf2 phosphorylation, facilitating nuclear translocation of this transcription factor ${ }^{47}$. In other studies, melanocortins were shown to inhibit JNK and p38 activity in HEK293 cells ${ }^{48}$ and in a model of Alzheimer's disease ${ }^{49}$, respectively. Considering this background, we could suggest that reduction in Nrf2 translocation induced by NDP-MSH could be a consequence of inhibition of JNK and p38 MAPK.

SOD activity is reduced in embryonic cardiomyocytes exposed to $\mathrm{PA}^{50}$. Concordantly, in our model PA lowered SOD activity and NDP-MSH treatment restored enzymatic activity to control levels in cultured astrocytes. Even in basal conditions NDP-MSH increased SOD activity 2 fold, thereby indicating that melanocortins have antioxidant action per se. Since NDP-MSH did not activate the Nrf2 pathway in our model, it is likely that the aforementioned transcription factor is not involved in the NDP-MSH effect on SOD activity. Studies indicate that PPAR- $\gamma$ activation increases SOD activity and synthesis in hippocampus ${ }^{51}$. Considering that our group has demonstrated that melanocortins induce expression of PPAR- $\gamma$ in astrocytes $^{23}$, we hypothesize that increased SOD activity could be mediated by this nuclear receptor. Further studies are needed to prove this hypothesis.

GSH is the main antioxidant compound of the cell, its synthesis rate limiting step catalyzed by $\gamma$-GCL. Our results show that NDP-MSH protected astrocytes against oxidative damage, stimulating GSH synthesis by increasing $\gamma-\mathrm{GCL}$ activity. Increased $\mathrm{GSH}$ release from astrocytes could also support survival of neurons ${ }^{52}$. Contrary to observations in other cell types $^{53}$, in our experiments PA did not modify $\gamma$-GCL activity despite increasing mRNA levels of both $\gamma$-GCL subunits. Conversely, NDP-MSH stimulated enzymatic activity without modifying mRNA levels. Given that $\gamma$-GCL activity is regulated at multiple levels ${ }^{54}$, it is possible that PA affects transcriptional activity whereas NDP-MSH induces posttranscriptional changes. Moreover, we recently reported that BDNF induces GSH synthesis

This article is protected by copyright. All rights reserved. 
in astrocytes ${ }^{31}$, and in the present work, we show that NDP-MSH prevented the reduction in BDNF expression induced by PA, suggesting that BDNF could be a mediator of NDP-MSH antioxidant effect in astrocytes.

Hypercaloric diets have extensive harmful effects, impacting multiple organs and systems including the CNS. In vivo studies show that high-fat feeding compromises learning and memory ${ }^{55,56}$, induces neuron death in the hippocampus and hypothalamus ${ }^{4}$, and triggers oxidative stress in different brain areas ${ }^{42}$. Therefore, we decided to test the effect of melanocortins on antioxidant defense using an in vivo model of high-fat feeding. Interestingly, animals fed a HFD did not gain more weight than SD-fed rats despite consuming more calories per day. Similar to our results several studies have shown no difference in body weight between animals, from different species and strains, fed a SD or a HFD for 8 weeks or longer. For instance, HFD exposure during 8 weeks affected body weight in Long-Evans and Wistar rats but not in Sprague-Dawley rats ${ }^{57}$. Similarly, Marques et al. indicate that Wistar rats increased body weight after consuming HFD for 4 weeks while Sprague-Dawley rats showed significant weight difference after 7 weeks. In addition, neither triglycerides nor insulin levels were affected by HFD in both strains ${ }^{58}$. C57BL/6J mice showed weight gain after 8 week in males and after 15 week in females ${ }^{59}$. On the other, no difference in body weight in C57BL/6J male mice after 16 weeks of HFD exposure has also been reported ${ }^{60}$. The same could apply for changes in cytokines release. We found no changes in TNF- $\alpha$ release in our experimental model. Accordingly, an increased in TNF- $\alpha$ levels was found after prolonged HFD feeding (24 weeks) in C57BL/6J mice ${ }^{61}$. Contradictory results about changes in IL-1 $\beta$ release have also been reported. HFD did not increased plasma levels of IL-1 $\beta$ in Sprague-Dawley rats after 8 weeks feeding a HFD ${ }^{57}$ while serum levels of IL-1 $\beta$ were markedly increased after 4 weeks but not at 16 weeks of HFD consumption in C57BL/6J mice ${ }^{60}$, indicating once more differences due to the experimental model. It is noteworthy that different HFD formulations have been used in the reports mentioned above, suggesting that several experimental issues could explain the absence of 
weight difference, including the use of different fat sources (lard, vegetable oil, margarine, etc), the different duration of diet exposure, species, and animal strain.

Since HFD did not produce alterations in biochemical or in hypothalamic parameters and did not increase TNF- $\alpha$ levels, we conclude that our in vivo model did not develop metabolic syndrome characteristics. However, given that high-fat feeding induces hypothalamic changes before the onset of peripheral inflammation, metabolic disturbances, and weight gain ${ }^{6}$, our model could be useful to evaluate early stages of this process. ICV treatment with NDP-MSH reduced calorie intake in SD-fed animals, as it was described previously ${ }^{62}$. This calorie intake reduction may account for reduced plasma glucose and triglyceride levels in SD-animals. Insulin concentration tended to be higher in HFD-fed rats, suggesting that these animals might develop insulin resistance, given that higher levels of insulin are needed to maintain glucose concentrations similar to control animals. It has been reported that central administration of $\alpha-\mathrm{MSH}$ improves insulin action on glucose uptake and production ${ }^{63}$. In view of the aforementioned, we could suggest that lower insulin levels are able to reduce blood glucose in HFD group treated with NDP-MSH. However, this effect is opposite to NDP-MSH action in SD-fed rats which show elevated insulin concentration.

Reported data on the impact of HFD on MC4R expression are contradictory. Some studies indicate that high-fat feeding does not change MC4R expression ${ }^{64}$, whereas others show that mice exposed to a HFD have higher mRNA levels of the receptor and better responsiveness to short-term treatments with MC4R agonists ${ }^{65}$. It is noteworthy that clinical studies with potent MC4R agonists were ineffective to treat obesity ${ }^{66}$. In line with this finding, several studies reported that HFD-fed rats showed a reduction in MC4R mRNA levels ${ }^{67}$, central resistance to $\mathrm{MC} 4 \mathrm{R}$ agonists ${ }^{64}$, and less binding to radio-labeled MC4R agonists in the hypothalamus ${ }^{68}$. Concordant with these studies, our results show that HFD exposure for 8 weeks reduced hypothalamic MC4R expression despite neither increasing body weight nor inducing metabolic syndrome, which reinforces the suggestion that hypothalamic changes occur before the onset of clinical symptoms.

This article is protected by copyright. All rights reserved. 
Regarding antioxidant response, we observed that NDP-MSH increased SOD activity in animals exposed to SD. Astrocytes could contribute, at least partially, to this effect, considering results observed in vitro. Although PA reduced SOD activity in astrocytes, HFD did not change hypothalamic SOD activity. Interestingly, in HFD group, NDP-MSH did not increase SOD activity. So, it is likely that the lack of melanocortin action on SOD activity in HFD-fed animals could be due to decreased MC4R expression in the hypothalamus. Expression of antioxidant genes was not modified by either diet or treatment, differing from in vitro experiments where PA stimulated Nrf2 pathway. This data could be explained by the presence of neurons and other cells that may be affected differently than astrocytes when challenged with components of a HFD, so that the effect of the diet on astrocytes alone is masked when the whole hypothalamus sis studied.

Learning deficits detected in obese animals have been linked to decreased BDNF expression $^{69}$. In our experimental model, we observed that HFD reduced BDNF gene expression and NDP-MSH treatment did not reverse this effect. Surprisingly, melanocortin ICV injection did not modify BDNF expression even in animals fed a SD, which differs from the effect we detected previously when $\alpha-\mathrm{MSH}$ was administered by intraperitoneal injection $^{39}$ and suggests that peripheral mediators may be needed for $\alpha-\mathrm{MSH}$ action on central BDNF expression.MC4R has been reported to be expressed in the gastrointestinal system, its activation inducing glucagon-like peptide 1 (GLP-1) expression ${ }^{70}$; an analogue of this hormone was shown to stimulate BDNF expression in the brain $^{71}$. Considering these data, GLP-1 could be considered as a possible mediator of the melanocortin effect on hypothalamic BDNF expression.

The hypothalamus is a key player in modulating feeding behavior and energy expenditure. Several studies have linked obesity with mitochondrial alterations which leads to oxidative stress $^{7}$. Then, excessive ROS production induces NFKB activation, the main mediator of the inflammatory response ${ }^{72}$, and modifies neuronal activity in the hypothalamus ${ }^{73}$. High-fat feeding and obesity are associated with hypothalamic inflammation and reactive gliosis in rodents. However, the role of astrocyte activation in response to metabolic and dietary clues

This article is protected by copyright. All rights reserved. 
is not fully understood. The present study demonstrated that NDP-MSH increased antioxidant enzyme activity and GSH levels in astrocytes, alleviating PA-induced oxidative stress and contributing to prevention of neuronal damage. In vivo, NDP-MSH exerts an antioxidant role by increasing SOD activity in SD-fed animals, suggesting that melanocortin antioxidant action added to their anti-inflammatory activity could protect neurons. However, NDP-MSH fails to show the same effect in the HFD group, in which hypothalamic MC4R expression is reduced. These results underscore the importance of $\alpha-\mathrm{MSH}$ in hypothalamic function and point to early disruptions in the melanocortin circuit in an HFD context as potential contributors to hypothalamic malfunction which may lead to metabolic disorders. Further research is needed in order to elucidate the mechanism of HFD-induced damage in the hypothalamus and how alteration of the melanocortin system contributes to perpetuate food intake dysregulation. Better understanding of these processes will allow us to develop new therapeutic strategies for metabolic diseases.

\section{REFERENCES}

1. Finkelstein EA, Khavjou OA, Thompson $\mathrm{H}$, et al. Obesity and severe obesity forecasts through 2030. American journal of preventive medicine. Jun 2012;42(6):563-570.

2. Thaler JP, Yi CX, Schur EA, et al. Obesity is associated with hypothalamic injury in rodents and humans. The Journal of clinical investigation. Jan 2012;122(1):153-162.

3. Milanski M, Degasperi G, Coope A, et al. Saturated fatty acids produce an inflammatory response predominantly through the activation of TLR4 signaling in hypothalamus: implications for the pathogenesis of obesity. The Journal of neuroscience : the official journal of the Society for Neuroscience. Jan 14 2009;29(2):359-370.

4. Moraes JC, Coope A, Morari J, et al. High-fat diet induces apoptosis of hypothalamic neurons. PloS one. 2009;4(4):e5045.

5. De Souza CT, Araujo EP, Bordin S, et al. Consumption of a fat-rich diet activates a proinflammatory response and induces insulin resistance in the hypothalamus. Endocrinology. Oct 2005;146(10):4192-4199.

This article is protected by copyright. All rights reserved. 
6. Thaler JP, Guyenet SJ, Dorfman MD, Wisse BE, Schwartz MW. Hypothalamic inflammation: marker or mechanism of obesity pathogenesis? Diabetes. Aug 2013;62(8):2629-2634.

7. Bondia-Pons I, Ryan L, Martinez JA. Oxidative stress and inflammation interactions in human obesity. Journal of physiology and biochemistry. Dec 2012;68(4):701-711.

8. de Mello AH, Costa AB, Engel JDG, Rezin GT. Mitochondrial dysfunction in obesity. Life sciences. Jan 1 2018;192:26-32.

9. Beltowski J, Wojcicka G, Gorny D, Marciniak A. The effect of dietary-induced obesity on lipid peroxidation, antioxidant enzymes and total plasma antioxidant capacity. Journal of physiology and pharmacology : an official journal of the Polish Physiological Society. Dec 2000;51(4 Pt 2):883-896.

10. Gupta S, Knight AG, Gupta S, Keller JN, Bruce-Keller AJ. Saturated long-chain fatty acids activate inflammatory signaling in astrocytes. J Neurochem. Mar 2012;120(6):10601071.

11. Wang Z, Liu D, Wang F, et al. Saturated fatty acids activate microglia via Toll-like receptor 4/NF-kappaB signalling. The British journal of nutrition. Jan 2012;107(2):229-241.

12. Wong KL, Wu YR, Cheng KS, et al. Palmitic acid-induced lipotoxicity and protection by (+)-catechin in rat cortical astrocytes. Pharmacological reports : PR. Dec 2014;66(6):1106-1113.

13. Belanger M, Allaman I, Magistretti PJ. Brain energy metabolism: focus on astrocyteneuron metabolic cooperation. Cell Metab. Dec 7 2011;14(6):724-738.

14. Chowen JA, Argente-Arizon P, Freire-Regatillo A, Frago LM, Horvath TL, Argente J. The role of astrocytes in the hypothalamic response and adaptation to metabolic signals. Prog Neurobiol. Sep 2016;144:68-87.

15. Yi CX, Gericke M, Kruger M, et al. High calorie diet triggers hypothalamic angiopathy. Molecular metabolism. 2012;1(1-2):95-100. 
16. Bull C, Freitas KC, Zou S, et al. Rat nucleus accumbens core astrocytes modulate reward and the motivation to self-administer ethanol after abstinence. Neuropsychopharmacology. Nov 2014;39(12):2835-2845.

17. Horvath TL, Sarman B, Garcia-Caceres C, et al. Synaptic input organization of the melanocortin system predicts diet-induced hypothalamic reactive gliosis and obesity. Proceedings of the National Academy of Sciences of the United States of America. Aug 17 2010;107(33):14875-14880.

18. Catania A, Lonati C, Sordi A, Carlin A, Leonardi P, Gatti S. The melanocortin system in control of inflammation. TheScientificWorldJournal. 2010;10:1840-1853.

19. Caruso C, Mohn C, Karara AL, et al. Alpha-melanocyte-stimulating hormone through melanocortin-4 receptor inhibits nitric oxide synthase and cyclooxygenase expression in the hypothalamus of male rats. Neuroendocrinology. 2004;79(5):278-286.

20. Huang Q, Tatro JB. Alpha-melanocyte stimulating hormone suppresses intracerebral tumor necrosis factor-alpha and interleukin-1beta gene expression following transient cerebral ischemia in mice. Neurosci Lett. Dec 16 2002;334(3):186-190.

21. Spaccapelo L, Galantucci M, Neri L, et al. Up-regulation of the canonical Wnt-3A and Sonic hedgehog signaling underlies melanocortin-induced neurogenesis after cerebral ischemia. European journal of pharmacology. May 05 2013;707(1-3):78-86.

22. Caruso C, Durand D, Schioth HB, Rey R, Seilicovich A, Lasaga M. Activation of melanocortin 4 receptors reduces the inflammatory response and prevents apoptosis induced by lipopolysaccharide and interferon-gamma in astrocytes. Endocrinology. Oct 2007;148(10):4918-4926 .

23. Carniglia L, Durand D, Caruso C, Lasaga M. Effect of NDP-alpha-MSH on PPARgamma and -beta expression and anti-inflammatory cytokine release in rat astrocytes and microglia. PloS one. 2013;8(2):e57313.

24. Kokot A, Metze D, Mouchet $\mathrm{N}$, et al. Alpha-melanocyte-stimulating hormone counteracts the suppressive effect of UVB on Nrf2 and Nrf-dependent gene expression in human skin. Endocrinology. Jul 2009;150(7):3197-3206.

This article is protected by copyright. All rights reserved. 
25. Pike Winer LS, Wu M. Rapid analysis of glycolytic and oxidative substrate flux of cancer cells in a microplate. PloS one. 2014;9(10):e109916.

26. Lee HJ, Cantu SM, Donoso AS, Choi MR, Peredo HA, Puyo AM. Metformin prevents vascular prostanoid release alterations induced by a high-fat diet in rats. Autonomic \& autacoid pharmacology. Jun 2017;37(3):37-43.

27. Paxinos G, Watson C. The rat brain in stereostaxic coordinates. United States of America: Academic Press; 1997.

28. Zhang $\mathrm{Y}, \mathrm{He} \mathrm{J}$, Liang B, Song Z. [The effect of triptolide on the proliferation of airway smooth muscle and the expression of c-fos and c-jun in asthmatic rats]. Zhonghua jie he he hu xi za zhi = Zhonghua jiehe he huxi zazhi = Chinese journal of tuberculosis and respiratory diseases. May 2002;25(5):280-283.

29. Correa F, Ljunggren E, Mallard C, Nilsson M, Weber SG, Sandberg M. The Nrf2inducible antioxidant defense in astrocytes can be both up- and down-regulated by activated microglia:Involvement of p38 MAPK. Glia. May 2011;59(5):785-799.

30. White CC, Viernes H, Krejsa CM, Botta D, Kavanagh TJ. Fluorescence-based microtiter plate assay for glutamate-cysteine ligase activity. Analytical biochemistry. Jul 15 2003;318(2):175-180.

31. Saba J, Turati J, Ramirez D, et al. Astrocyte truncated-TrkB mediates BDNF antiapoptotic effect leading to neuroprotection. J Neurochem. May 312018.

32. Mosmann T. Rapid colorimetric assay for cellular growth and survival: application to proliferation and cytotoxicity assays. Journal of immunological methods. Dec 16 1983;65(12):55-63.

33. Kundu J, Kim DH, Kundu JK, Chun KS. Thymoquinone induces heme oxygenase-1 expression in HaCaT cells via Nrf2/ARE activation: Akt and AMPKalpha as upstream targets. Food and chemical toxicology : an international journal published for the British Industrial Biological Research Association. Mar 2014;65:18-26.

34. Caruso C, Carniglia L, Durand D, Gonzalez PV, Scimonelli TN, Lasaga M. Melanocortin 4 receptor activation induces brain-derived neurotrophic factor expression in 
rat astrocytes through cyclic AMP-protein kinase A pathway. Molecular and cellular endocrinology. Jan 2 2012;348(1):47-54.

35. Livak KJ, Schmittgen TD. Analysis of relative gene expression data using real-time quantitative PCR and the 2(-Delta Delta C(T)) Method. Methods. Dec 2001;25(4):402-408.

36. Bryan HK, Olayanju A, Goldring CE, Park BK. The Nrf2 cell defence pathway: Keap1dependent and -independent mechanisms of regulation. Biochemical pharmacology. Mar 15 2013;85(6):705-717.

37. Dringen R. Metabolism and functions of glutathione in brain. Prog Neurobiol. Dec 2000;62(6):649-671 .

38. Xu B, Goulding $\mathrm{EH}$, Zang $\mathrm{K}$, et al. Brain-derived neurotrophic factor regulates energy balance downstream of melanocortin-4 receptor. Nature neuroscience. Jul 2003;6(7):736742.

39. Ramirez D, Saba J, Carniglia L, Durand D, Lasaga M, Caruso C. Melanocortin 4 receptor activates ERK-cFos pathway to increase brain-derived neurotrophic factor expression in rat astrocytes and hypothalamus. Molecular and cellular endocrinology. Aug 15 2015;411:28-37.

40. Boden G. Obesity and free fatty acids. Endocrinology and metabolism clinics of North America. Sep 2008;37(3):635-646, viii-ix.

41. Miller AA, Spencer SJ. Obesity and neuroinflammation: a pathway to cognitive impairment. Brain, behavior, and immunity. Nov 2014;42:10-21.

42. Freeman LR, Haley-Zitlin V, Rosenberger DS, Granholm AC. Damaging effects of a high-fat diet to the brain and cognition: a review of proposed mechanisms. Nutritional neuroscience. Nov 2014;17(6):241-251.

43. Ng YW, Say YH. Palmitic acid induces neurotoxicity and gliatoxicity in SH-SY5Y human neuroblastoma and T98G human glioblastoma cells. PeerJ. 2018;6:e4696.

44. Cui $Y$, Wang $Q$, Yi X, Zhang X. Effects of Fatty Acids on CYP2A5 and Nrf2 Expression in Mouse Primary Hepatocytes. Biochemical genetics. Feb 2016;54(1):29-40.

This article is protected by copyright. All rights reserved. 
45. Wang X, Liu JZ, Hu JX, et al. ROS-activated p38 MAPK/ERK-Akt cascade plays a central role in palmitic acid-stimulated hepatocyte proliferation. Free radical biology \& medicine. Jul 15 2011;51(2):539-551.

46. Park JS, Kang DH, Lee DH, Bae SH. Concerted action of p62 and Nrf2 protects cells from palmitic acid-induced lipotoxicity. Biochemical and biophysical research communications. Oct 09 2015;466(1):131-137.

47. Vargas MR, Johnson JA. The Nrf2-ARE cytoprotective pathway in astrocytes. Expert reviews in molecular medicine. 2009;11:e17.

48. Chai B, Li JY, Zhang W, Wang H, Mulholland MW. Melanocortin-4 receptor activation inhibits c-Jun N-terminal kinase activity and promotes insulin signaling. Peptides. Jun 2009;30(6):1098-1104.

49. Giuliani D, Galantucci M, Neri L, et al. Melanocortins protect against brain damage and counteract cognitive decline in a transgenic mouse model of moderate Alzheimers disease. European journal of pharmacology. Oct 05 2014;740:144-150.

50. Li J, Zhou Y, Zhang W, Bao C, Xie Z. Relief of oxidative stress and cardiomyocyte apoptosis by using curcumin nanoparticles. Colloids and surfaces. B, Biointerfaces. May 01 2017; 153:174-182.

51. $\mathrm{YuX}$, Shao XG, Sun $\mathrm{H}$, et al. Activation of cerebral peroxisome proliferator-activated receptors gamma exerts neuroprotection by inhibiting oxidative stress following pilocarpineinduced status epilepticus. Brain Res. Mar 20 2008;1200:146-158.

52. Gegg ME, Clark JB, Heales SJ. Co-culture of neurones with glutathione deficient astrocytes leads to increased neuronal susceptibility to nitric oxide and increased glutamatecysteine ligase activity. Brain Res. Mar 2 2005;1036(1-2):1-6.

53. Kim MH, Kim EH, Jung HS, Yang D, Park EY, Jun HS. EX4 stabilizes and activates Nrf2 via PKCdelta, contributing to the prevention of oxidative stress-induced pancreatic beta cell damage. Toxicology and applied pharmacology. Jan 15 2017;315:60-69.

54. Lu SC. Regulation of glutathione synthesis. Molecular aspects of medicine. Feb-Apr $2009 ; 30(1-2): 42-59$.

This article is protected by copyright. All rights reserved. 
55. Jurdak N, Lichtenstein AH, Kanarek RB. Diet-induced obesity and spatial cognition in young male rats. Nutritional neuroscience. Apr 2008;11(2):48-54.

56. Stranahan AM, Mattson MP. Impact of energy intake and expenditure on neuronal plasticity. Neuromolecular medicine. 2008;10(4):209-218.

57. Song Z, Xie W, Chen S, et al. High-fat diet increases pain behaviors in rats with or without obesity. Scientific reports. Sep 4 2017;7(1):10350.

58. Marques C, Meireles M, Norberto S, et al. High-fat diet-induced obesity Rat model: a comparison between Wistar and Sprague-Dawley Rat. Adipocyte. Jan-Mar 2016;5(1):11-21.

59. Hwang LL, Wang $\mathrm{CH}$, Li TL, et al. Sex differences in high-fat diet-induced obesity, metabolic alterations and learning, and synaptic plasticity deficits in mice. Obesity. Mar 2010;18(3):463-469 .

60. Vinuesa A, Pomilio C, Menafra M, et al. Juvenile exposure to a high fat diet promotes behavioral and limbic alterations in the absence of obesity. Psychoneuroendocrinology. Oct 2016;72:22-33.

61. van der Heijden RA, Sheedfar F, Morrison MC, et al. High-fat diet induced obesity primes inflammation in adipose tissue prior to liver in C57BL/6j mice. Aging. Apr 2015;7(4):256-268.

62. Poggioli R, Vergoni AV, Bertolini A. ACTH-(1-24) and alpha-MSH antagonize feeding behavior stimulated by kappa opiate agonists. Peptides. Sep-Oct 1986;7(5):843-848.

63. Obici S, Feng Z, Tan J, Liu L, Karkanias G, Rossetti L. Central melanocortin receptors regulate insulin action. The Journal of clinical investigation. Oct 2001;108(7):10791085

64. Clegg DJ, Benoit SC, Air EL, et al. Increased dietary fat attenuates the anorexic effects of intracerebroventricular injections of MTII. Endocrinology. Jul 2003;144(7):29412946.

65. Stofkova A, Skurlova M, Kiss A, Zelezna B, Zorad S, Jurcovicova J. Activation of hypothalamic NPY, AgRP, MC4R, AND IL-6 mRNA levels in young Lewis rats with early-life diet-induced obesity. Endocrine regulations. Jul 2009;43(3):99-106.

This article is protected by copyright. All rights reserved. 
66. Krishna R, Gumbiner B, Stevens $C$, et al. Potent and selective agonism of the melanocortin receptor 4 with MK-0493 does not induce weight loss in obese human subjects: energy intake predicts lack of weight loss efficacy. Clinical pharmacology and therapeutics. Dec 2009;86(6):659-666.

67. Gutierrez-Aguilar R, Kim DH, Woods SC, Seeley RJ. Expression of new loci associated with obesity in diet-induced obese rats: from genetics to physiology. Obesity. Feb 2012;20(2):306-312.

68. Irani BG, Dunn-Meynell AA, Levin BE. Altered hypothalamic leptin, insulin, and melanocortin binding associated with moderate-fat diet and predisposition to obesity. Endocrinology. Jan 2007;148(1):310-316.

69. Wu A, Ying Z, Gomez-Pinilla F. The interplay between oxidative stress and brainderived neurotrophic factor modulates the outcome of a saturated fat diet on synaptic plasticity and cognition. The European journal of neuroscience. Apr 2004;19(7):1699-1707.

70. Panaro BL, Tough IR, Engelstoft MS, et al. The melanocortin-4 receptor is expressed in enteroendocrine $L$ cells and regulates the release of peptide $Y Y$ and glucagon-like peptide 1 in vivo. Cell Metab. Dec 2 2014;20(6):1018-1029.

71. Abdelwahed OM, Tork OM, Gamal El Din MM, Rashed L, Zickri M. Effect of glucagon-like peptide-1 analogue; Exendin-4, on cognitive functions in type 2 diabetes mellitus; possible modulation of brain derived neurotrophic factor and brain Visfatin. Brain research bulletin. May 2018;139:67-80.

72. Munoz A, Costa M. Nutritionally mediated oxidative stress and inflammation. Oxidative medicine and cellular longevity. 2013;2013:610950.

73. Cunarro J, Casado S, Lugilde J, Tovar S. Hypothalamic Mitochondrial Dysfunction as a Target in Obesity and Metabolic Disease. Frontiers in endocrinology. 2018;9:283.

This article is protected by copyright. All rights reserved. 


\section{FIGURE LEGENDS}

Figure 1 - NDP-MSH prevented PA-induced ROS production through MC4R. (a) Astrocytes were treated with increasing PA doses for $24 \mathrm{~h}$. Cell viability was determined by MTT assay. Values are the mean \pm SEM of 8 determinations per group of 1 representative experiment of 2 independent ones. Data were analyzed by comparing each dose of PA with its respective control by Student's t test $* * * p<0.001$ vs. control. (b) Astrocytes were treated with increasing concentrations of PA for $2 \mathrm{~h}$ and ROS production was determined. Values are the mean \pm SEM of 8 determinations per group of 1 representative experiment of 2 independent ones. Data were analyzed by comparing each dose of PA with its respective control by Student's t test $* * * p<0.001$ vs. control. (c) Astrocytes were incubated with PA $(100 \mu \mathrm{M})$ in presence or absence of NDP-MSH $(0.1 \mu \mathrm{M})$ and/or JKC363 $(10 \mathrm{nM})$ for $2 \mathrm{~h}$ and ROS production was determined. Values are the mean \pm SEM of fluorescence intensity (arbitrary units) of 8 determinations per group of 1 representative experiment of 3 independent ones. Data were analyzed by one way ANOVA followed by Bonferroni's multiple comparison test $\mathrm{F}_{(5,42)}=99.47 ;{ }^{* * *} \mathrm{p}<0.001$ vs. control; ${ }^{\wedge} \mathrm{p}<0.05 ;{ }^{\wedge} p<0.01$ vs. PA+NDP-MSH.

Figure 2 - NDP-MSH prevented Nrf2 nuclear translocation and Nrf2-dependent gene expression induced by PA and stimulated BDNF expression. Astrocytes were incubated for $6 \mathrm{~h}$ with PA $(100 \mu \mathrm{M})$ in presence or absence of NDP-MSH $(0.1 \mu \mathrm{M})$. (a) Representative images for Nrf2 immunostaining of 1 representative experiment of 3 independent ones. (b) Nuclear fluorescence intensity (arbitrary units) was quantified using ImageJ Software. Data represent mean \pm SEM of $100-175$ cells per group of 1 representative experiment of 3 independent ones and were analyzed by one way ANOVA followed by Bonferroni's multiple comparison test $\mathrm{F}_{(3,577)}=235.4 ; * * * p<0.001$ vs. control; ${ }^{\wedge \wedge} \mathrm{p}<0.001$ vs. PA. (c) GCLc, (d GCLm, and (e) HO-1 expression was determined by RT-qPCR after 6 h-treatment with PA $(100 \mu \mathrm{M})$ in presence or absence of NDP-MSH $(0.1 \mu \mathrm{M})$. Data represent mean \pm SEM of $4-5$ independent experiments and were analyzed by one way ANOVA, GCLc: $F_{(2,14)}=16.42$, 
GCLm: $F_{(2,9)}=1.92, \mathrm{HO}-1:$ GCLm: $F_{(2,15)}=3.818,{ }^{*} p<0.05$, ***p $<0.001$ vs. control; ${ }^{\wedge} p<0.01$ vs. PA. (f) Astrocytes were incubated for $1 \mathrm{~h}$ with PA $(100 \mu \mathrm{M})$ in presence or absence of NDP-MSH $(0.1 \mu \mathrm{M})$ and BDNF expression was determined by RT-qPCR. Data represent mean \pm SEM of 3 independent experiments and were analyzed by one way ANOVA, $F_{(3,12)}=$ 7.188; * $p<0.05$ vs. control; ${ }^{\wedge} p<0.05$ vs. PA.

Figure 3 - NDP-MSH increased SOD and $\gamma$-GCL activity. (a) Astrocytes were treated for $24 \mathrm{~h}$ with PA $(100 \mu \mathrm{M})$ in presence or absence of NDP-MSH $(0.1 \mu \mathrm{M})$ and SOD activity was measured using Fridovich's technique as described in Material and Methods. Data represent mean \pm SEM of 3 independent experiments and were analyzed by one way ANOVA followed by Bonferroni's multiple comparison test, $\mathrm{F}_{(3,12)}=20.49$, $* \mathrm{p}<0.05$, $* * p<0.01$ vs. control; ${ }^{\wedge} \mathrm{p}<0.05$ vs. PA. (b) Cells were incubated with increasing doses of NDP-MSH for $24 \mathrm{~h}$ and $\gamma$ GCL activity was measured by Correa's technique as described in Material and Methods. Data represent mean \pm SEM of 3 independent experiments and were analyzed by one way ANOVA followed by Bonferroni's multiple comparison test, $F_{(3,10)}=15.66, * p<0.05$, $* * p<0.01, * * * p<0.001$ vs. control. (c) Astrocytes were incubated with PA $(100 \mu \mathrm{M})$ in presence or absence of NDP-MSH $(0.1 \mu \mathrm{M})$ for $24 \mathrm{~h}$ and $\gamma$-GCL activity was measured by Correa's technique as described in Material and Methods. Data represent mean \pm SEM of 4 independent experiments and were analyzed by Kruskal-Wallis test followed by Dunn's multiple comparison test $* p<0.05$ vs. control; ${ }^{\wedge} p<0.05$ vs. PA.

Figure 4 - NDP-MSH increased GSH levels. (a) Astrocytes were treated with NDP-MSH $(0.1 \mu \mathrm{M})$ for $24 \mathrm{~h}$ and $\mathrm{GSH}$ levels were determined by fluorescence assay. Data represent mean \pm SEM of 4 independent experiments and were analyzed by Student's $t$ test $* * * p<0.001$ vs. control. Astrocytes were exposed to PA $(100 \mu \mathrm{M})$ in presence or absence of NDP-MSH $(0.1 \mu \mathrm{M})$ for $2 \mathrm{~h}$ to determine intracellular (b) and extracellular (c) GSH levels. In both cases, data represent mean \pm SEM of 3 independent experiments and were analyzed 
by one way ANOVA followed by Bonferroni's multiple comparison test, intracellular GSH $F_{(3 \text {, }}$ 23) $=4.187$, extracellular GSH: $F_{(3,24)}=2.821, * p<0.05$ vs. control.

Figure 5 - Calorie intake and weight gain of animals fed a SD or a HFD. (a) Calorie intake was calculated by multiplying energy concentration of each diet $(\mathrm{kcal} / \mathrm{g})$ by the amount of food (g) consumed per day. (b) Weight gain was calculated as the difference between initial and final body weight. Data represent mean \pm SEM of $n=11-15$ animals per group and were analyzed by Student's $t$ test. $* * * p<0.001$ vs. SD

Figure 6 - Effect of NDP-MSH on calorie intake, biochemical parameters and TNF- $\alpha$ levels in animals fed SD or HFD. Animals were exposed to either SD (5\% fat) or HFD (50\% fat) for 8 weeks. Rats were fasted overnight and on the day of euthanasia were injected ICV with either saline or NDP-MSH. After $4 \mathrm{~h}$ animals were killed. (a) Calorie intake was calculated by multiplying energy concentration of each diet $(\mathrm{kcal} / \mathrm{g})$ by the amount of food (g) consumed in the last $4 \mathrm{~h}$ of the experiment. (b) Glucose, (c) tryglicerides, (d) insulin, and (e) cholesterol were measured in trunk blood after $4 \mathrm{~h}$ treatment with either saline or NDP-MSH. (f) Hypothalamic TNF- $\alpha$ levels were determined by ELISA. Data represent the mean \pm SEM of $n=5-8$ animals per group and were analyzed by two way ANOVA $* p<0.05$; $* * p<0.01 ; * * * p<0.001$ vs. SD saline; ${ }^{\wedge \wedge} p<<0.001$ vs. HFD saline.

Figure 7 - Effect of NDP-MSH on hypothalamic antioxidant response in animals fed with SD or HFD. (a) SOD activity was measured using Fridovich's technique as described in Materials and Methods. (b) Nrf2, (c) GCLc, and (d) GCLm gene expression was determined by RT-qPCR. Data represent the mean \pm SEM of $n=5-8$ animals per group and were analyzed by two way ANOVA * $p<0.05$ vs. SD saline.

This article is protected by copyright. All rights reserved. 
Figure 8 - Effect of NDP-MSH on hypothalamic BDNF and MC4R gene expression in animals fed SD or HFD. (a) BDNF and (b) MC4R expression was determined by RT-qPCR. Data represent the mean \pm SEM of $n=5-8$ animals per group and were analyzed by two way ANOVA * $p<0.05$ vs. SD saline; ${ }^{\wedge} p<0.05$ vs. SD NDP-MSH.

Figure 9 - Graph depicting the antioxidant action of NDP-MSH in astrocytes. In vitro stimulation of astroglial MC4R increased SOD and $\gamma$-GCL activity, BDNF expression and GSH levels, alleviating PA-induced ROS production in astrocytes and possibly contributing to neuron protection.

Table 1.Primer sequences used for RT-qPCR

\section{$\begin{array}{lll}\text { Gene } & \text { Forward primer sequence } & \text { Reverse primer sequence }\end{array}$}

\begin{tabular}{c|c|c|} 
HO-1 & 5'-TCTATCGTGCTCGCATGAACA-3' & 5'-TCTTCTGTCACCCTGTGCTTGA-3' \\
GCLC & 5'-TCTGCCCAATTGTTATGGCTTT-3' & 5'-GTCTGACACGTAGCCTCGGTAA-3' \\
GCLm & 5'-CGTCACTGAGGCGTGAATGT-3' & 5'-CGCCAGGGAGGTACTCAAAC-3' \\
Nrf2 & 5'-CAAATCCCACCTTGAACACAGAT-3' & 5'-TGGGCTCTGCTAGGAAAGCA-3' \\
MC4R & 5'-CCAACTGCAGCCTTCCAACT-3' & 5'-GCCCCGAGTGGTTTTTCTC-3' \\
BDNF & 5'-GATGAGGACCAGAAGGTTCG-3' & 5'-TCCAGCAGAAAGAGCAGAGG-3' \\
HPRT & 5'-CTCATGGACTGATTATGGACAGGAC-3' & 5'-GCAGGTCAGCAAAGAACTTATAGCC-3'
\end{tabular}

This article is protected by copyright. All rights reserved. 

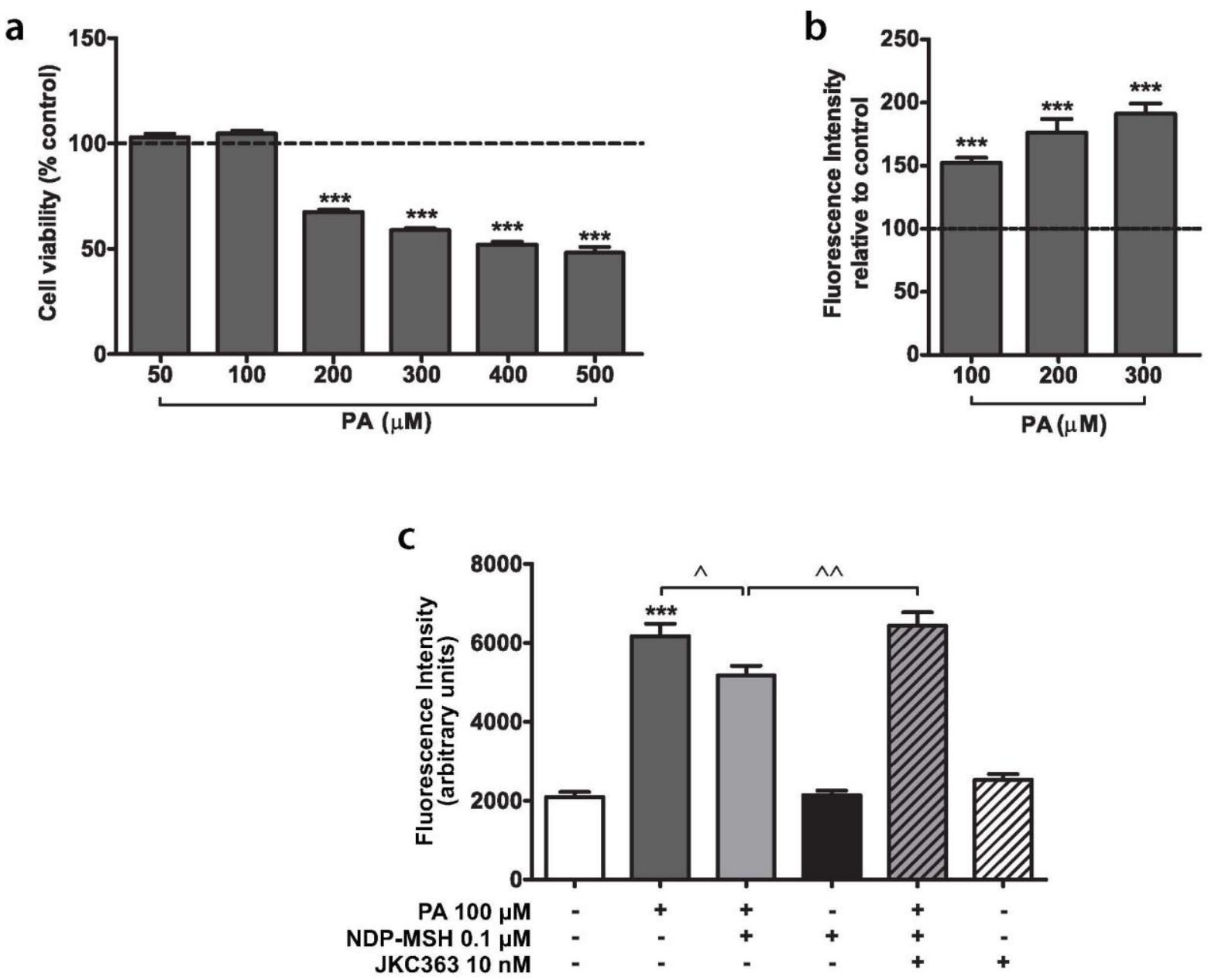

This article is protected by copyright. All rights reserved. 
a
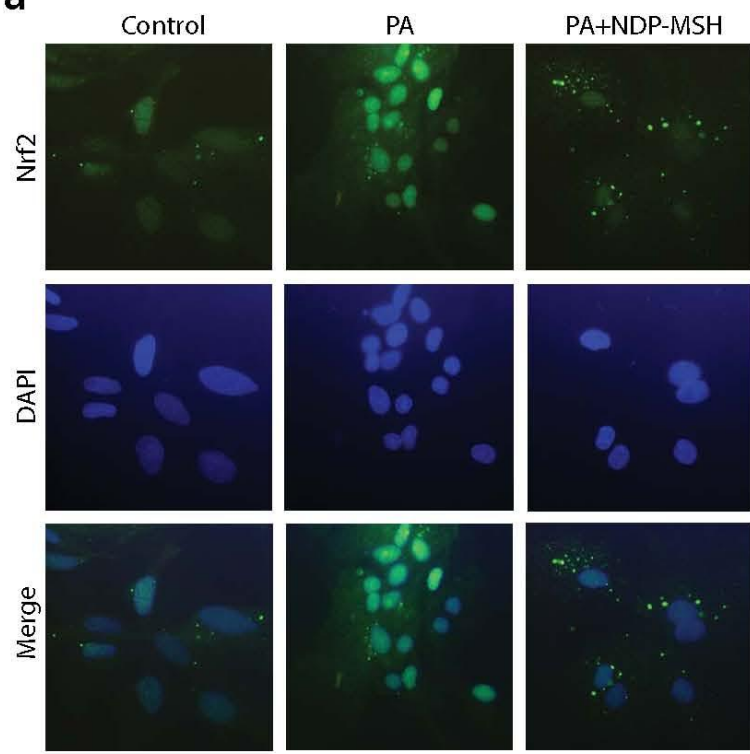

c

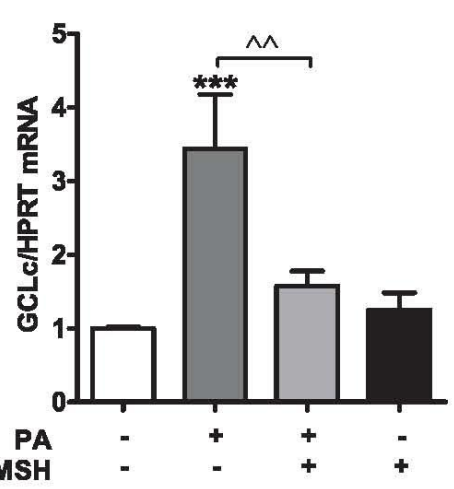

e

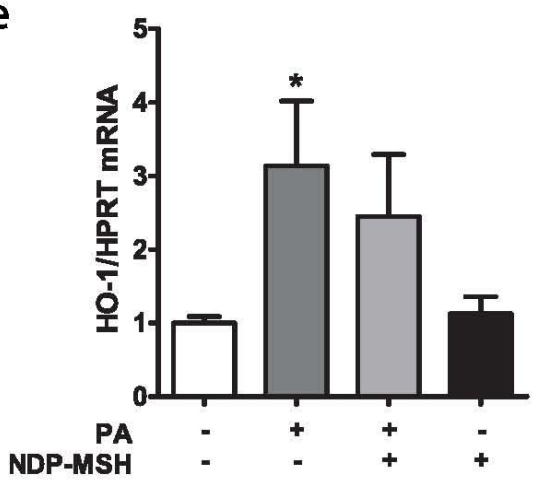

NDP-MSH
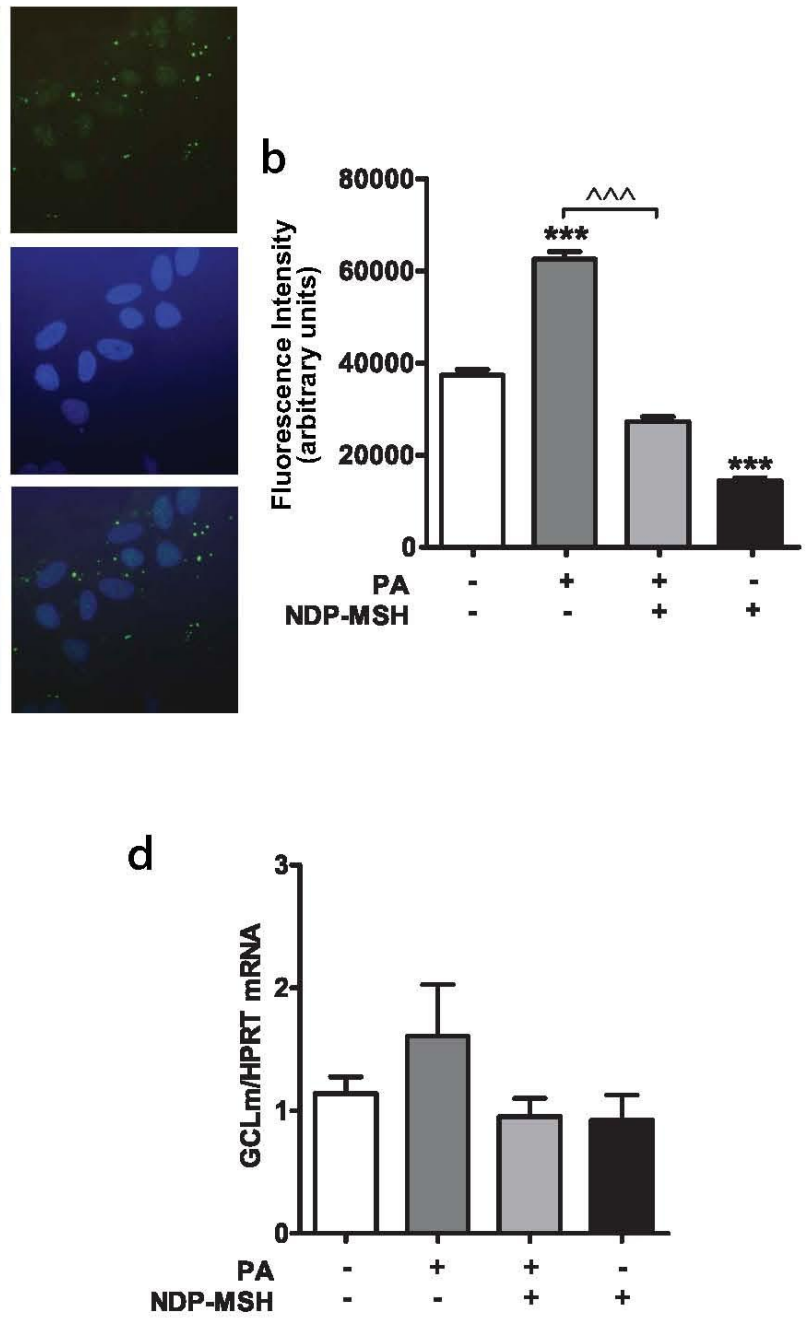

f

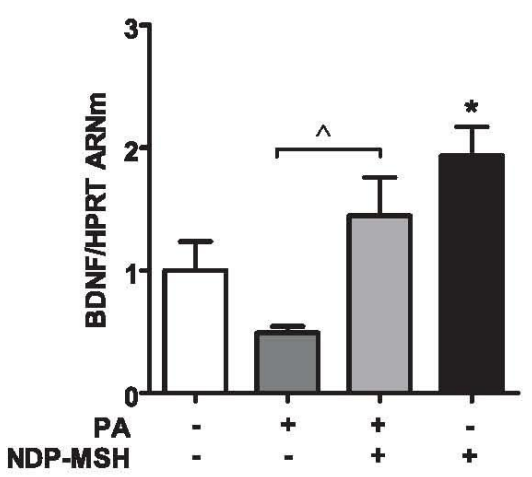



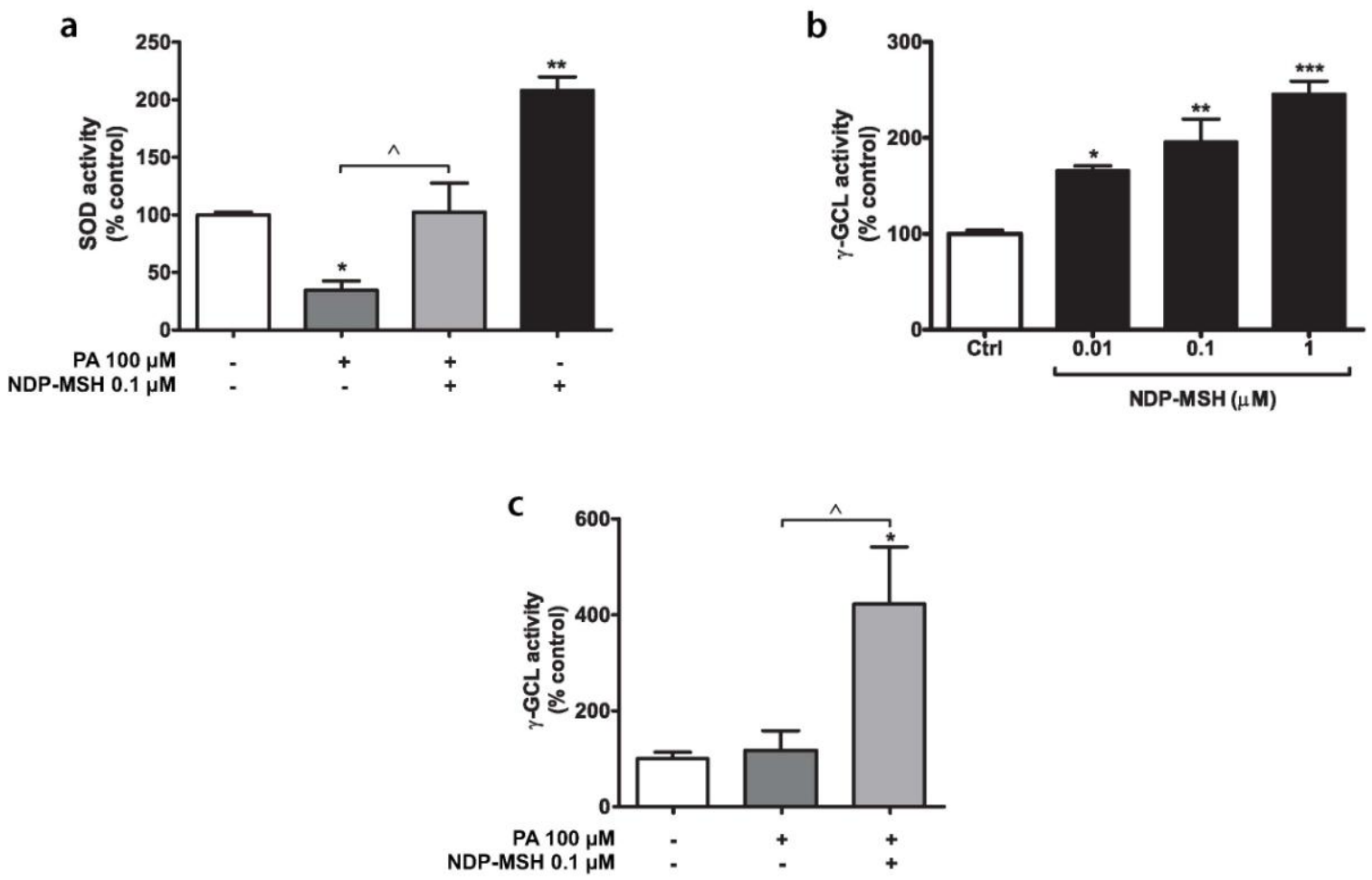

This article is protected by copyright. All rights reserved. 

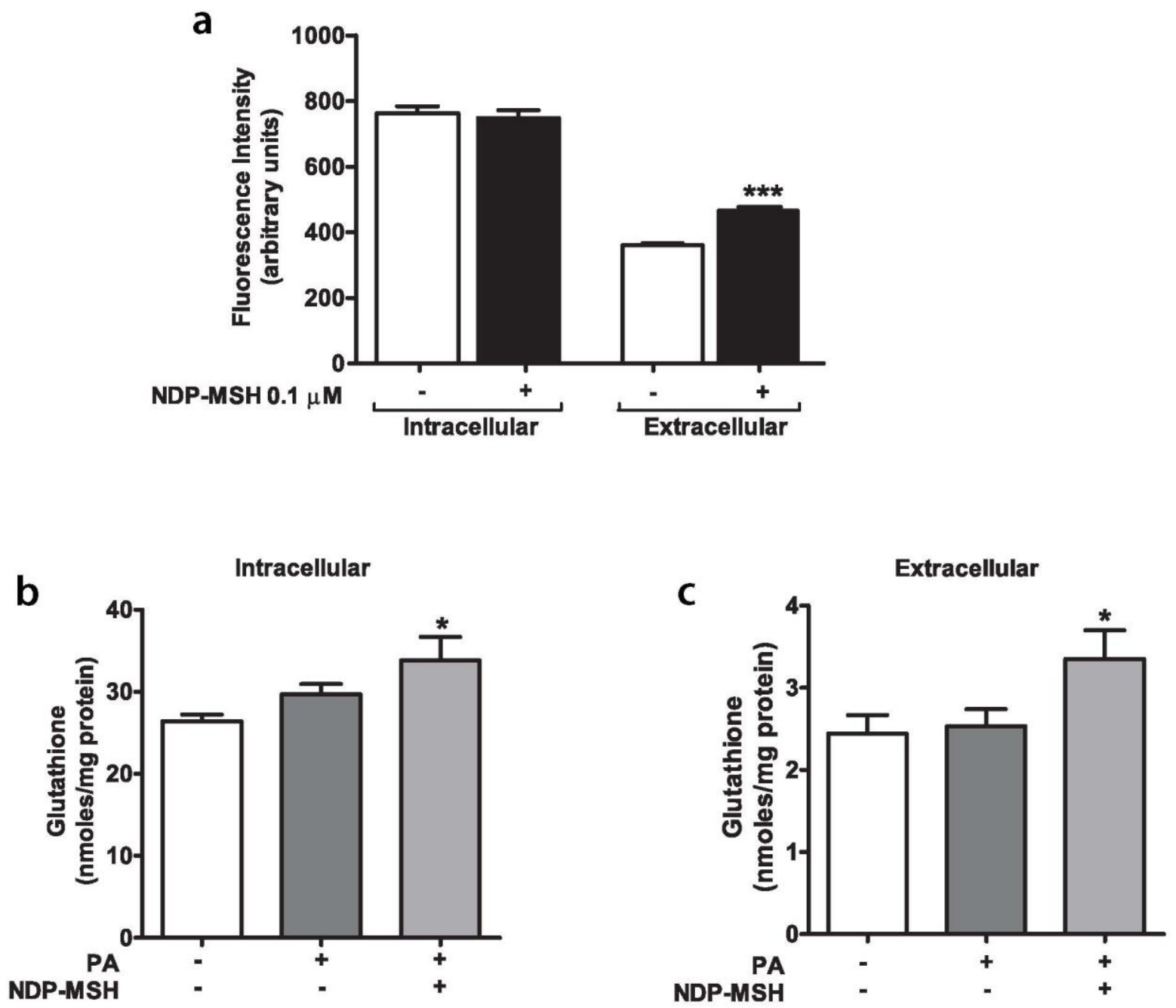

This article is protected by copyright. All rights reserved. 

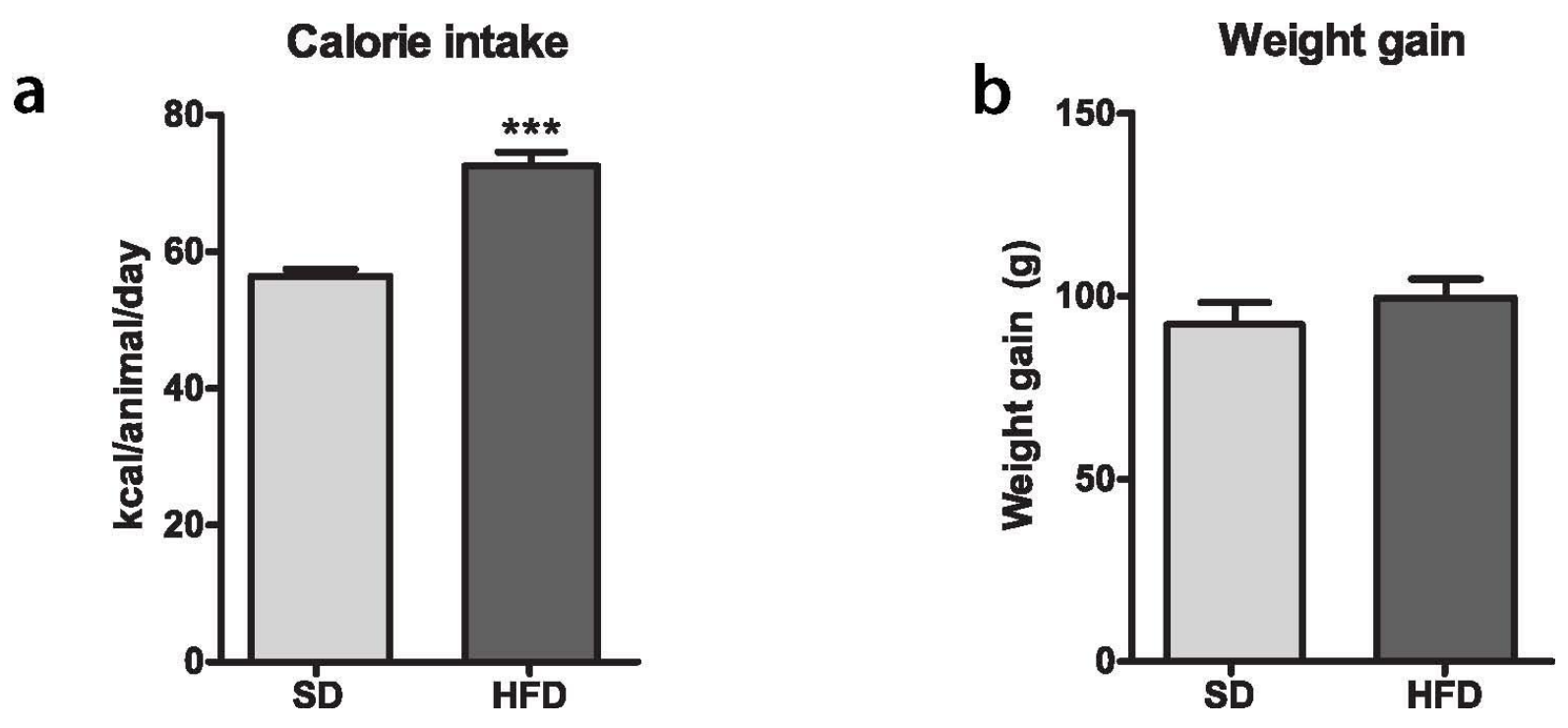

This article is protected by copyright. All rights reserved. 

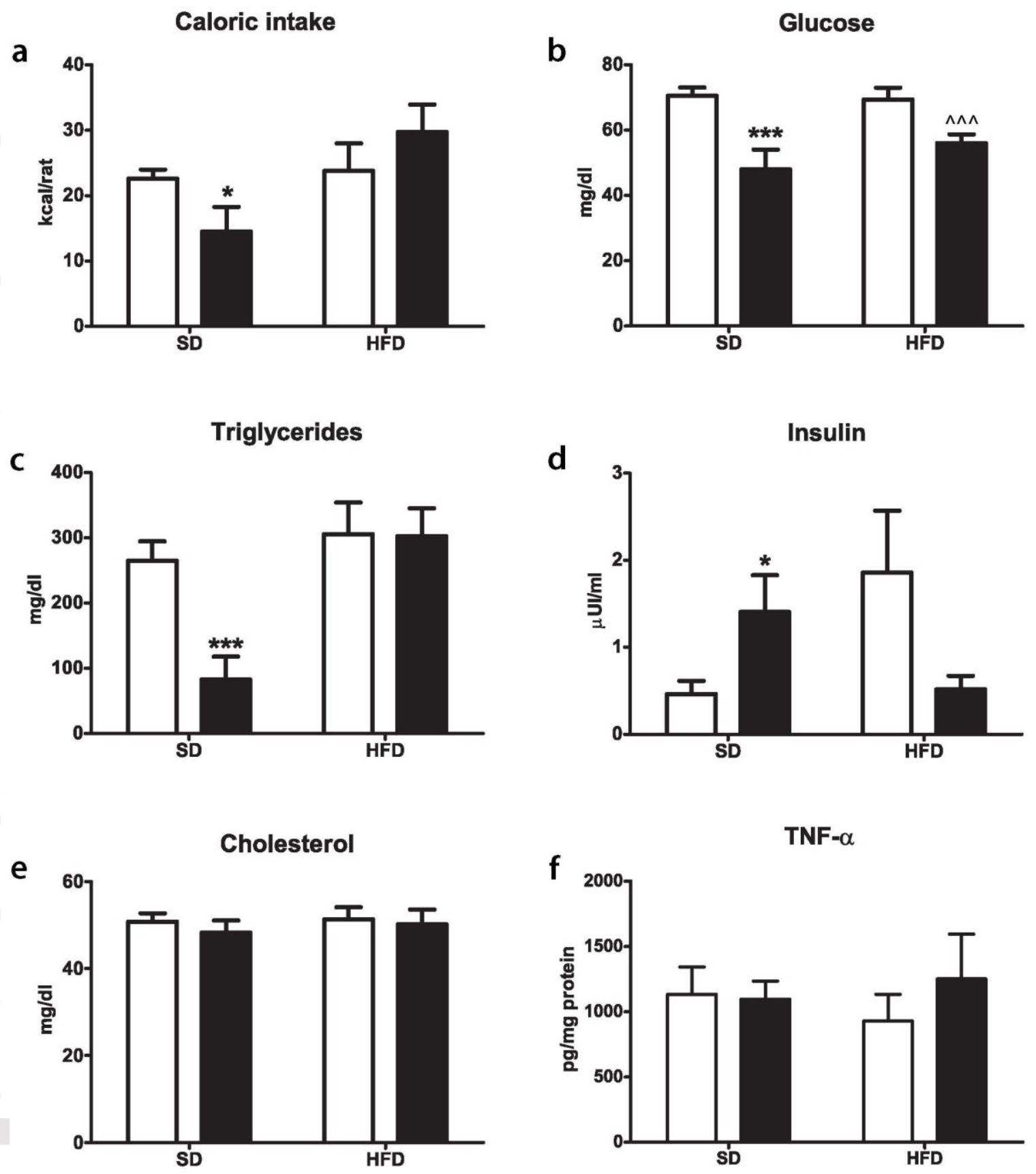

$\square$ Saline $\square$ NDP-MSH 

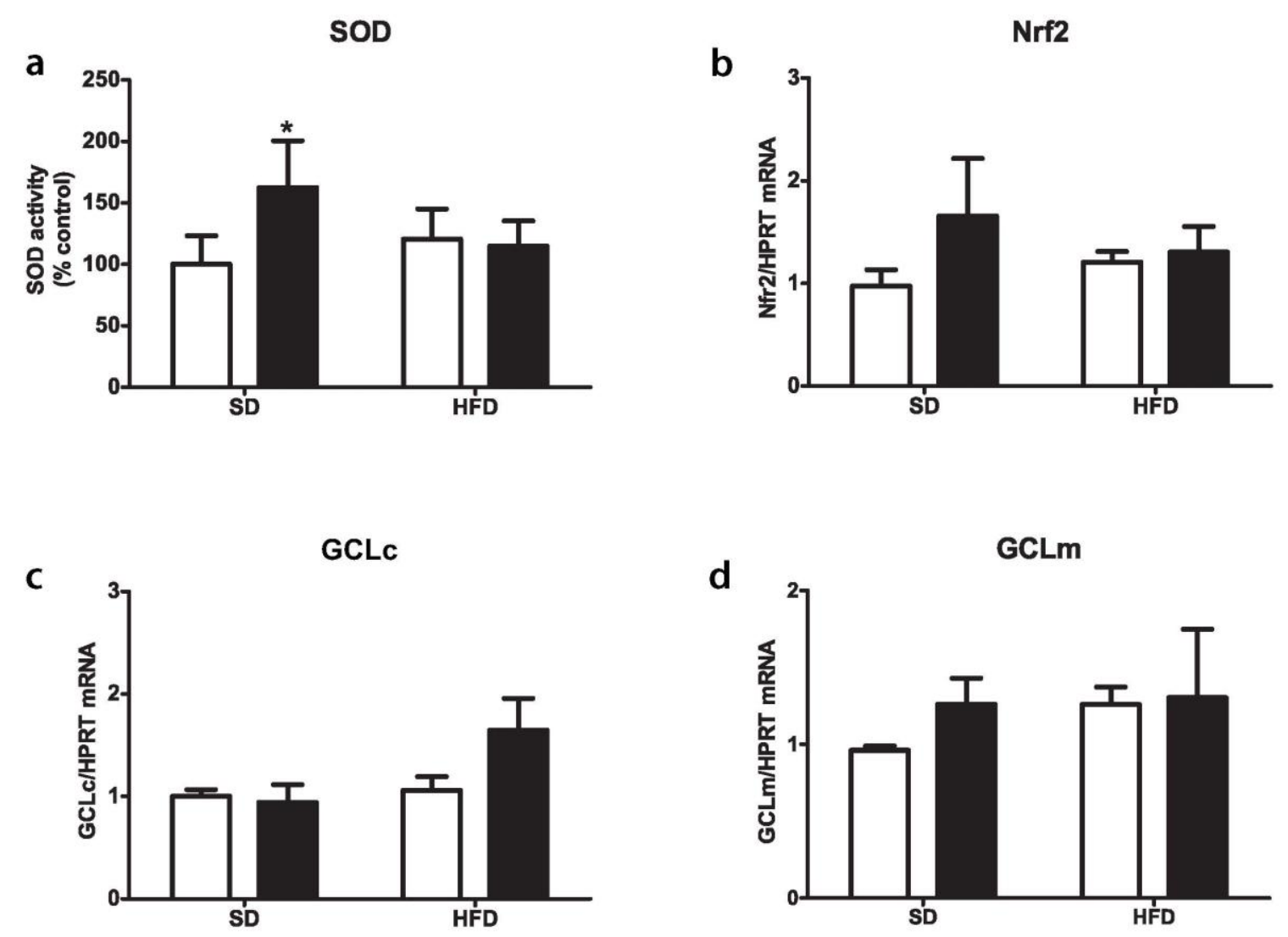

$\square$ Saline 

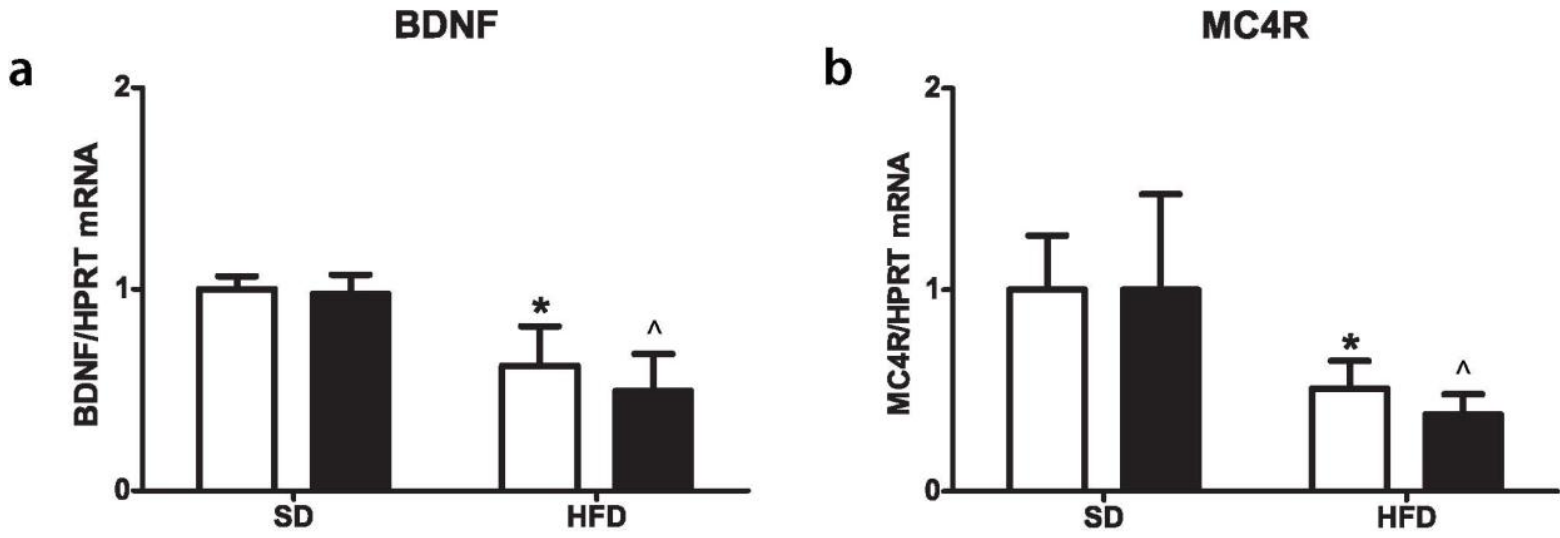

$\square$ Saline

NDP-MSH

This article is protected by copyright. All rights reserved. 


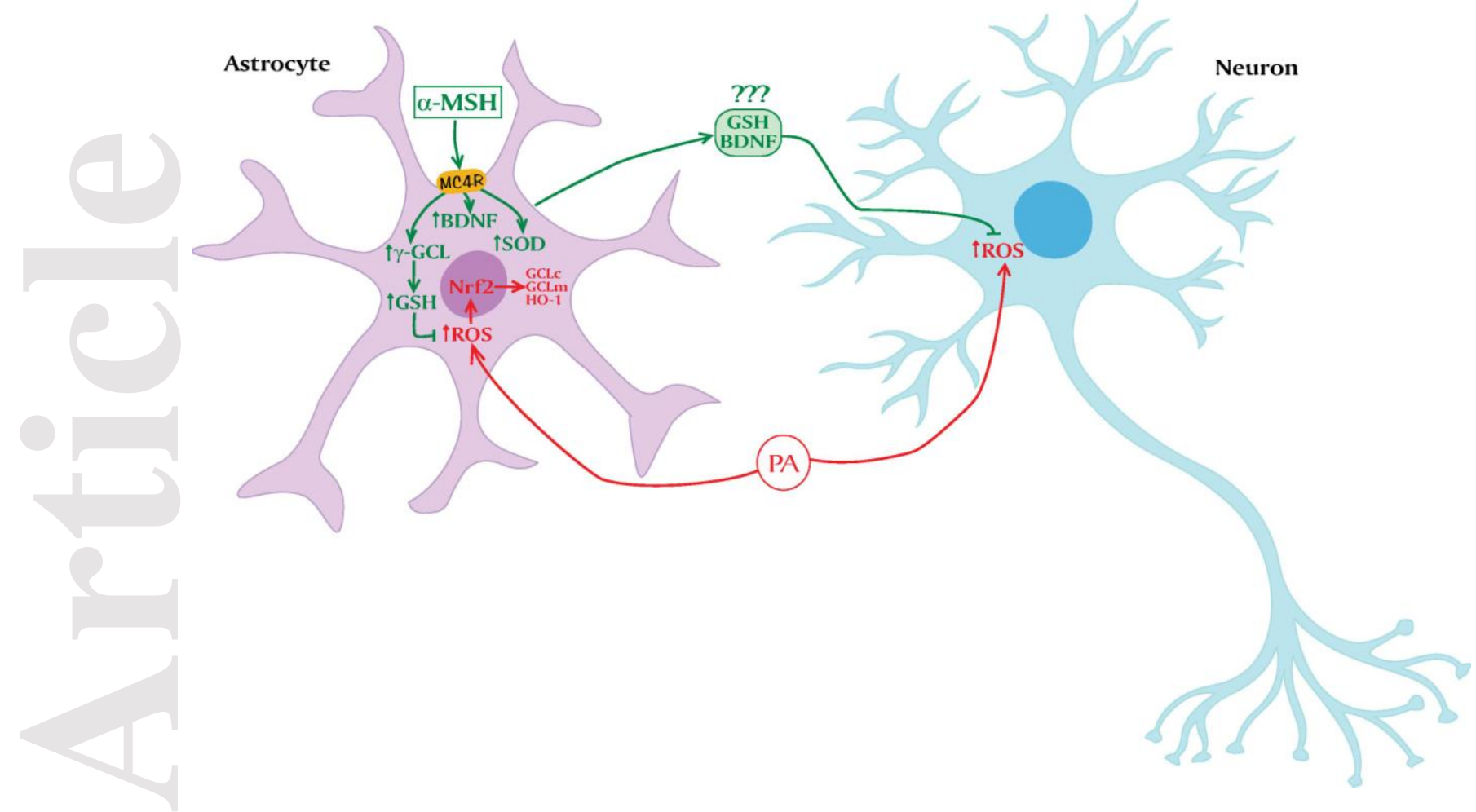

This article is protected by copyright. All rights reserved. 